\title{
Aspectos impactantes no desempenho energético de habitações de interesse social brasileiras: revisão de literatura
}

\author{
Aspects impacting on the energy performance of Brazilian \\ social housing: a literature review
}

\begin{abstract}
Mateus V. Bavaresco
Hamilton Yair Ortiz Cuchivague

Alexandre Schinazi

Enedir Ghisi

N

os últimos dez anos, o setor de habitações de interesse social (HIS) no Brasil foi impulsionado pela criação do Programa "Minha Casa, Minha Vida" (PMCMV). Apesar do Programa ter permitido a construção de grande quantidade de habitações em todo o território nacional, avaliações em campo ressaltam falhas quanto à adequação das habitações aos climas locais. A inadequação pode resultar em baixos níveis de eficiência energética das HIS e insatisfação de seus moradores. Desta forma, o objetivo deste estudo é revisar a literatura nacional dos últimos dez anos (de 2009 a 2019) a fim de determinar os aspectos que influenciam a eficiência energética das HIS. A síntese dessas informações é necessária para consolidar o conhecimento produzido até aqui e facilitar o avanço nessa área. Espera-se que este estudo favoreça futuras decisões de diferentes partes interessadas: pesquisadores podem definir seus escopos de estudo considerando o que já foi desenvolvido, projetistas podem aplicar na prática critérios de eficiência energética e de design centrados nos usuários, e responsáveis por políticas públicas podem vincular a aprovação de projetos de HIS a parâmetros de eficiência energética.

Palavras-chave: Habitações de Interesse Social. Programa Minha Casa Minha Vida. Eficiência energética. Desempenho termoenergético.

${ }^{1}$ Mateus V. Bavaresco ${ }^{1}$ Universidade Federal de Santa

Catarina

Florianópolis - SC - Brasil

${ }^{2}$ Hamilton Yair Ortiz Cuchivague ${ }^{2}$ Mitsidi Projetos São Paulo - SP - Brasil

${ }^{3}$ Alexandre Schinazi ${ }^{3}$ Mitsidi Projetos São Paulo - SP - Brasil

${ }^{4}$ Enedir Ghisi ${ }^{4}$ Universidade Federal de Santa Florianópolis - SC - Brasil

Recebido em 01/10/19 Aceito em 01/06/20

\section{Abstract}

In the last ten years, the social housing sector in Brazil has been driven by the Programme "Minha Casa, Minha Vida" ("My House, My Life"). Although the Programme allowed the construction of a great number of dwellings throughout the country, field assessments have highlighted failures such as lack of climate suitability. Such an inadequacy can result in low levels of energy efficiency and the dissatisfaction of residents. Thus, the aim of this study is to review the national literature from the last ten years (from $2009 \mathrm{up}$ to 2019) in order to determine the most impacting parameters for the energy efficiency of social housing. A synthesis of this information is necessary to consolidate the knowledge produced so far and to facilitate progress in this area. This study is expected to help future decisions by different stakeholders: researchers can define future goals by considering what has already been done, designers can apply user-centric design and energy efficiency criteria in practice, and policy makers can link the approval of social housing designs to energy efficiency parameters.

Keywords: Social Housing. Programme "My House, My Life". Energy efficiency. Thermal and energy performance.
\end{abstract}




\section{Introdução}

O Governo Federal investe no setor de habitações de interesse social (HIS) há várias décadas. Rubin e Bolfe (2014) contextualizaram as HIS na história nacional, e percebem-se dois maiores incentivadores nesse cenário: primeiro, a criação do Banco Nacional da Habitação (BNH) em 1964; e segundo, a criação do Programa "Minha Casa, Minha Vida" (PMCMV) em 2009. Destaca-se que, apesar de o BNH ter ficado amplamente conhecido nessa área, o Governo Federal já construía HIS a partir de outras iniciativas antes de sua instituição. Entretanto, a literatura evidencia pouca evolução nas habitações entregues ao longo dos anos. Logsdon (2012), por exemplo, comparou dois empreendimentos construídos em Cuiabá, um em 1949 e outro em 2010. A comparação evidencia a padronização histórica das HIS: a autora questiona a qualidade dos projetos e afirma que os mesmos são replicados há décadas, sem a consideração de melhorias necessárias já apresentadas em estudos e avaliações de campo. No início do PMCMV a literatura já mostrava os benefícios da inclusão de medidas de eficiência energética nas habitações: Bodach e Hamhaber (2010) concluíram que adequar as habitações aos climas ajudaria a amortecer o rápido crescimento da demanda energética de países emergentes. Os autores afirmaram que, ao se aprimorar os níveis de eficiência energética no setor de habitações, o mercado da construção civil como um todo poderia atingir maiores níveis de eficiência energética e sustentabilidade.

Mesmo com a padronização histórica das HIS, é evidente que os investimentos no setor de HIS resultam em impactos positivos. Além de contribuir com a redução do deficit habitacional, Gonçalves Júnior et al. (2014) concluíram que os investimentos em HIS impactam positivamente na economia nacional, principalmente em relação à geração de empregos. Entretanto, o impacto positivo do investimento não pode excluir a frequente preocupação com a qualidade e a eficiência das habitações construídas. De maneira geral, percebe-se que a necessidade de acelerar a construção e reduzir os custos das HIS resulta em projetos padronizados que desconsideram as características climáticas do local onde serão construídos (DALBEM et al., 2017). A falta de consideração quanto ao local onde o empreendimento será construído afeta, especialmente, o desempenho termoenergético das habitações. Morais e Labaki (2017) destacam essa deficiência das habitações do PMCMV e classificam a falha tanto em relação aos materiais empregados quanto às estratégias de projeto.

Caso as edificações sejam construídas desconsiderando o clima do local da implantação, baixos níveis de desempenho termoenergético serão observados ao longo de sua vida útil. Consequentemente, os moradores apresentarão insatisfação quanto às residências. É necessário, portanto, que os futuros empreendimentos sejam adequados às características climáticas dos locais onde serão construídos a fim de melhorar o desempenho termoenergético das habitações e aumentar os níveis de satisfação de seus moradores. Como exposto por Moraga (2017), tendo em vista a forte relação entre características da envoltória e desempenho das habitações, escolhas inadequadas na fase de projeto (etapa curta em relação à vida útil total de uma edificação) podem resultar em desempenhos insatisfatórios durante os 50 anos estimados para a vida útil da edificação. Nesse aspecto, o processo de tomada de decisão baseado em análises de incerteza (SILVA; ALMEIDA; GHISI, 2016) e a otimização multi-objetivo baseada em algoritmos genéticos (BRE et al., 2016) foram propostos para melhorar os níveis de desempenho termoenergético de edificações residenciais. Os resultados evidenciam variação de características construtivas ideais de acordo com os climas locais. De maneira similar, Dalbem et al. (2019) evidenciam a necessidade de se adequar as HIS aos climas locais e apresentam a possibilidade de incluir critérios passivos de concepção de habitações inseridas em climas do sul do Brasil. Além da preocupação quanto ao desempenho das edificações atuais, a literatura também evidencia a necessidade de se considerar os cenários climáticos futuros a fim de determinar o desempenho das habitações. Quando se considera o impacto de mudanças climáticas, a necessidade de melhorar o desempenho das HIS se torna ainda mais evidente (INVIDIATA; GHISI, 2016; INVIDIATA; LAVAGNA; GHISI, 2018; MONTES, 2016; TRIANA; LAMBERTS; SASSI, 2016, 2018).

Tendo em vista a complexidade dos fatores que envolvem a obtenção de HIS energeticamente eficientes, é necessário agrupar o conhecimento já produzido para informar diferentes profissionais do setor da construção civil nacional e consolidar as melhorias necessárias nessa área. Nesse âmbito, como resultado de uma revisão de literatura ampla, Kowaltowski et al. (2015) apresentaram diversos aspectos relevantes ao Programa "Minha Casa, Minha Vida". Os autores destacaram o grande interesse da comunidade científica em relação ao PMCMV; entretanto, ressaltaram que apenas $8 \%$ dos trabalhos encontrados apresentam relação com tópicos sobre conforto ambiental e eficiência energética.

Desta forma, esta revisão de literatura visa aprofundar os estudos nessa área, enfocando-se os aspectos que impactam o desempenho energético das HIS no Brasil. O objetivo deste trabalho é revisar a literatura dos últimos dez anos a fim de determinar os aspectos de maior importância para a eficiência energética das HIS. 
Primeiramente, apresenta-se uma breve caracterização das HIS construídas por meio do PMCMV para a Faixa de renda 1 - atualmente, essa faixa corresponde a beneficiários cujo teto de renda familiar não ultrapasse R\$ 1.800/mês (CAIXA..., 2020). A caracterização foi realizada com base no banco de dados da Secretaria Nacional de Habitação. Por fim, são apresentados os aspectos definidos com base na revisão de literatura como impactantes no desempenho energético das HIS. Com esse estudo, espera-se informar as diferentes partes interessadas sobre fatores que podem contribuir com a melhoria do desempenho das HIS existentes no Brasil.

\section{Caracterização das habitações do PMCMV}

A Secretaria Nacional de Habitação (SNH) do Ministério do Desenvolvimento Regional apresenta uma Base de Dados (MINISTÉRIO..., 2020) com todos os empreendimentos do PMCMV desde seu início em 2009. Informações como a localização geográfica, valores e data de contrato, número de unidades habitacionais entregues e dados das construtoras responsáveis são apresentados. Além disso, as tipologias dos imóveis são apresentadas parcialmente ( $87 \%$ dos dados possuem essa informação), e divididas entre: "Apartamento", "Casa", "Village/Casa sobreposta" e "Misto". Os projetos sem essa informação, correspondentes a $17 \%$ da base de dados, tiveram sua tipologia classificada como "Desconhecida". A tipologia "mista" corresponde aos empreendimentos com mais de uma tipologia - combinações de casas e apartamentos, por exemplo. Apesar da indefinição quanto às características da tipologia "mista", ressalta-se que esta é a que representa a menor quantidade dentre as habitações construídas $(1,1 \%)$. A partir das informações apresentadas na base de dados, realizou-se análise gráfica para contextualizar o estoque contratado ao longo do PMCMV em termos de disposição no tempo (Figura 1) e localização geográfica (Figura 2). As indicações numéricas da Figura 2 representam o total de unidades habitacionais (UHs) construídas, mostrando as quantidades de habitações construídas de acordo com o diâmetro de cada gráfico de setor. Percebe-se que os estados com mais contratos firmados foram São Paulo (226.465 UHs), Bahia (178.785 UHs) e Minas Gerais (123.164 UHs).

Há grande variação entre estados: comparando-se as proporções de Santa Catarina às do Acre, percebe-se que enquanto em SC quase a totalidade de UHs corresponde a apartamentos, no AC as casas são a tipologia predominante. Essas informações apresentam um panorama geral das predominâncias por estado, e podem ser cruzadas com dados de deficit habitacional, populações em áreas de grande adensamento urbano, etc., para buscar relações entre as características das UHs do PMCMV e as necessidades dessas localidades. Ao identificar as tipologias mais comuns de acordo com as regiões geográficas (análise apresentada na Figura 3), percebeu-se que nas regiões sul e sudeste a maioria das UHs construídas são apartamentos. Nas demais regiões - norte, nordeste e centro-oeste - a tipologia mais comuns é a casa. Como tendência geral, percebeuse que em todas as regiões geográficas brasileiras a grande maioria das UHs corresponde a apartamentos e casas. Quando se faz recortes por estado, alguns casos que não seguem essa tendência se destacam: tipologia mista no Amazonas e no Amapá, e casas sobrepostas na Bahia. Com exceção desses três estados, os demais são majoritariamente constituídos por apartamentos e casas.

A tipologia do imóvel é impactante no desempenho termoenergético das habitações, uma vez que diferentes características interferem nas trocas de calor da edificação com o meio externo. Desta forma, é interessante conhecer variações entre características construtivas de habitações situadas nas oito zonas bioclimáticas (ZBs) brasileiras. Portanto, utilizou-se a base de dados da SNH para determinar as ZBs das cidades listadas, combinando-se informações da NBR 15220 (ABNT, 2005) e do programa computacional ZBBR (RORIZ..., 2005). O resultado é apresentado na Figura 4. Para facilitar a interpretação das informações, os gráficos de setores (Figura 4b) foram posicionados no centro geométrico das áreas referentes às ZBs (Figura 4a). Destaca-se que, como a NBR 15220 (ABNT, 2005) apresenta número limitado de municípios classificados, criou-se uma base de dados com as ZBs de todos os municípios listados nos registros da SNH. 
Figura 1 - Total de UHs contratadas de acordo com o ano do PMCMV

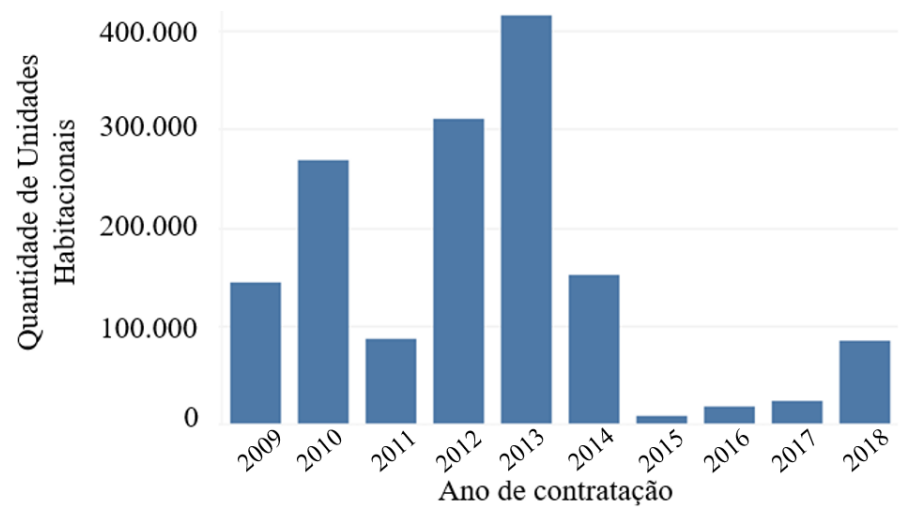

Fonte: adaptado de MDR (MINISTÉRIO..., 2020).

Figura 2 - Caracterização das tipologias das UHs do PMCMV de acordo com o estado

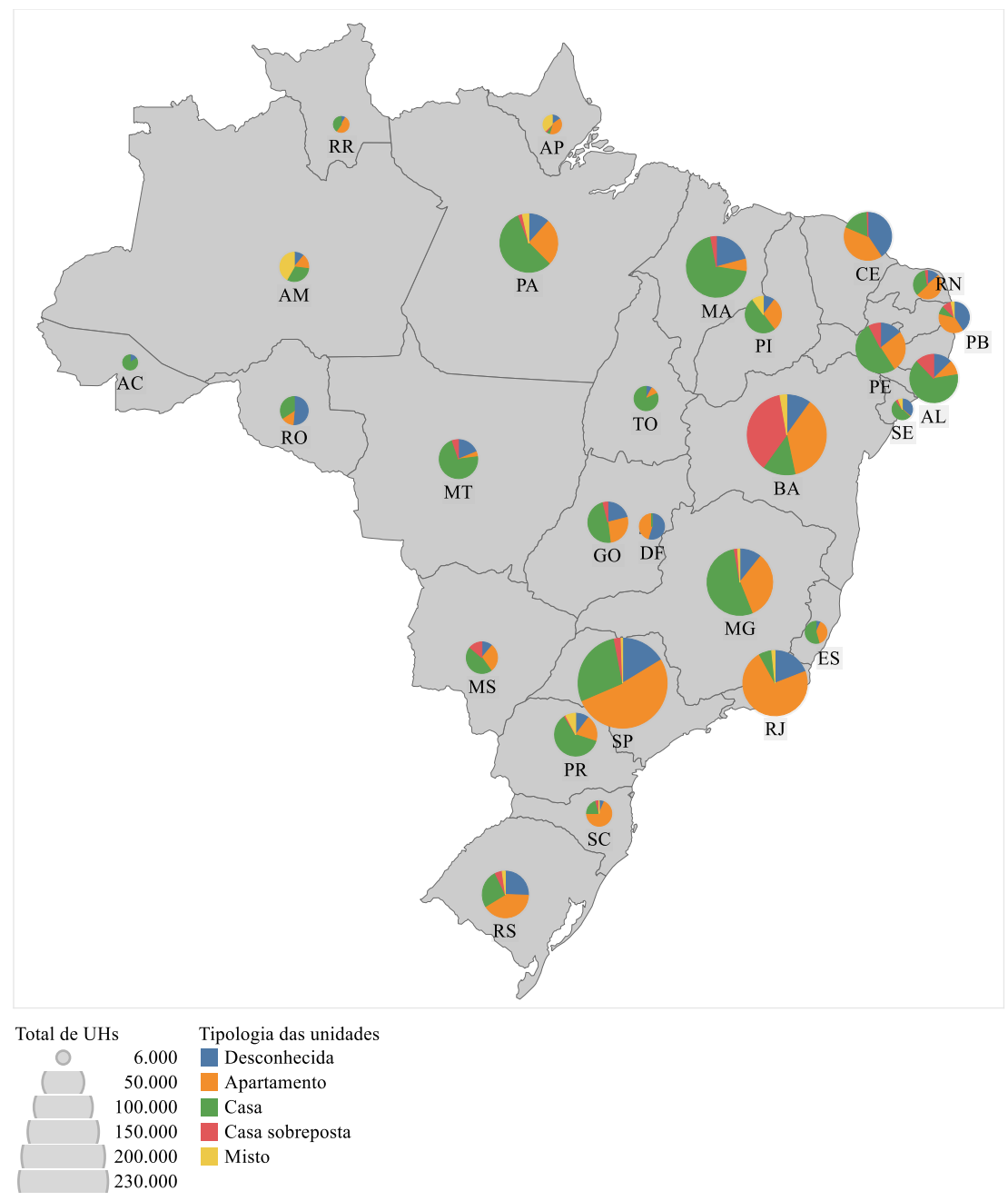

Fonte: adaptado de MDR (MINISTÉRIO..., 2020). 
Figura 3 - Caracterização das tipologias das UHs de acordo com as regiões geográficas brasileiras

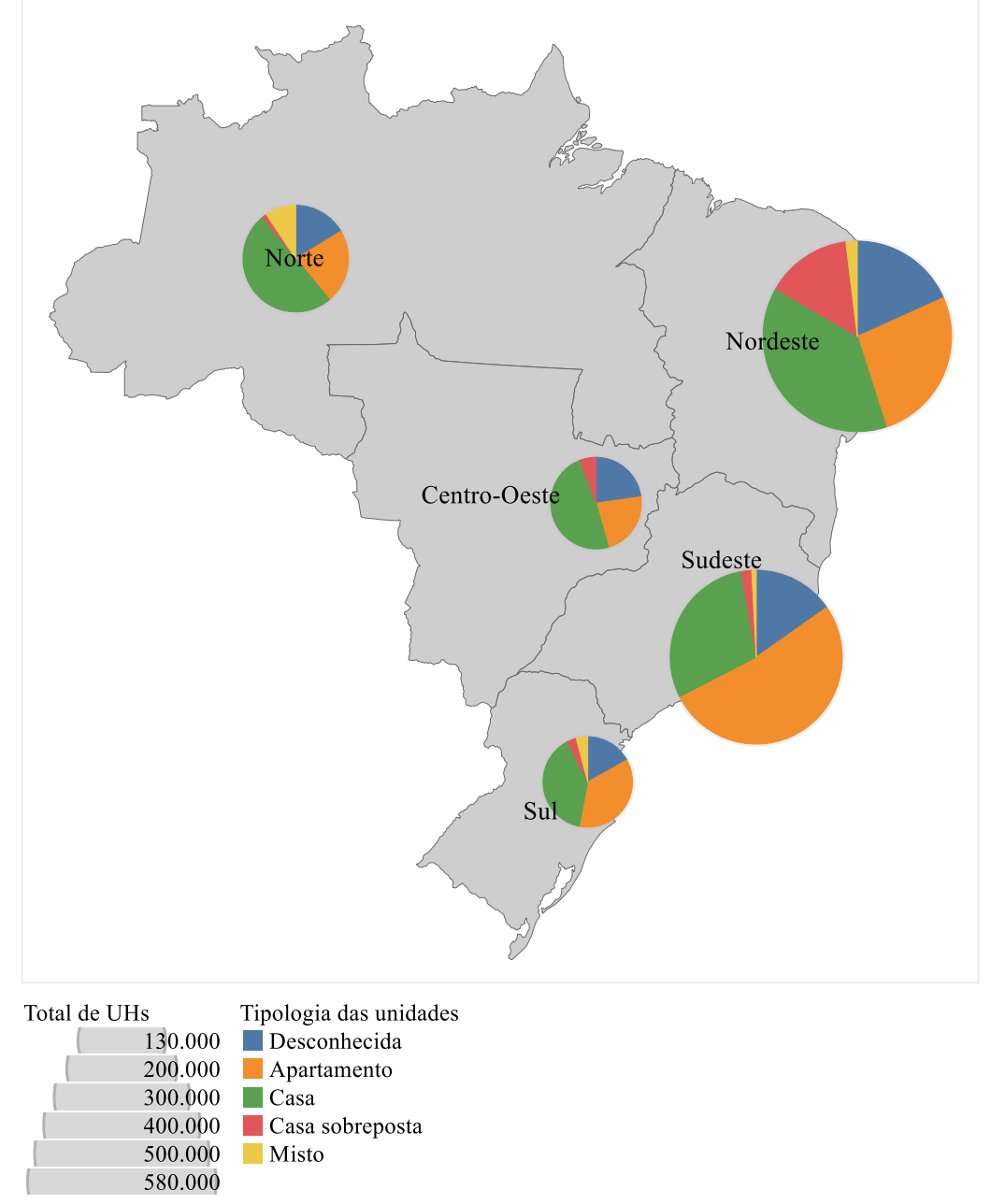

Fonte: adaptado de MDR (MINISTÉRIO..., 2020).

Figura 4 - (a) Ilustração do Zoneamento Bioclimático brasileiro; e (b) Caracterização das tipologias das UHs nas diferentes Zonas Bioclimáticas

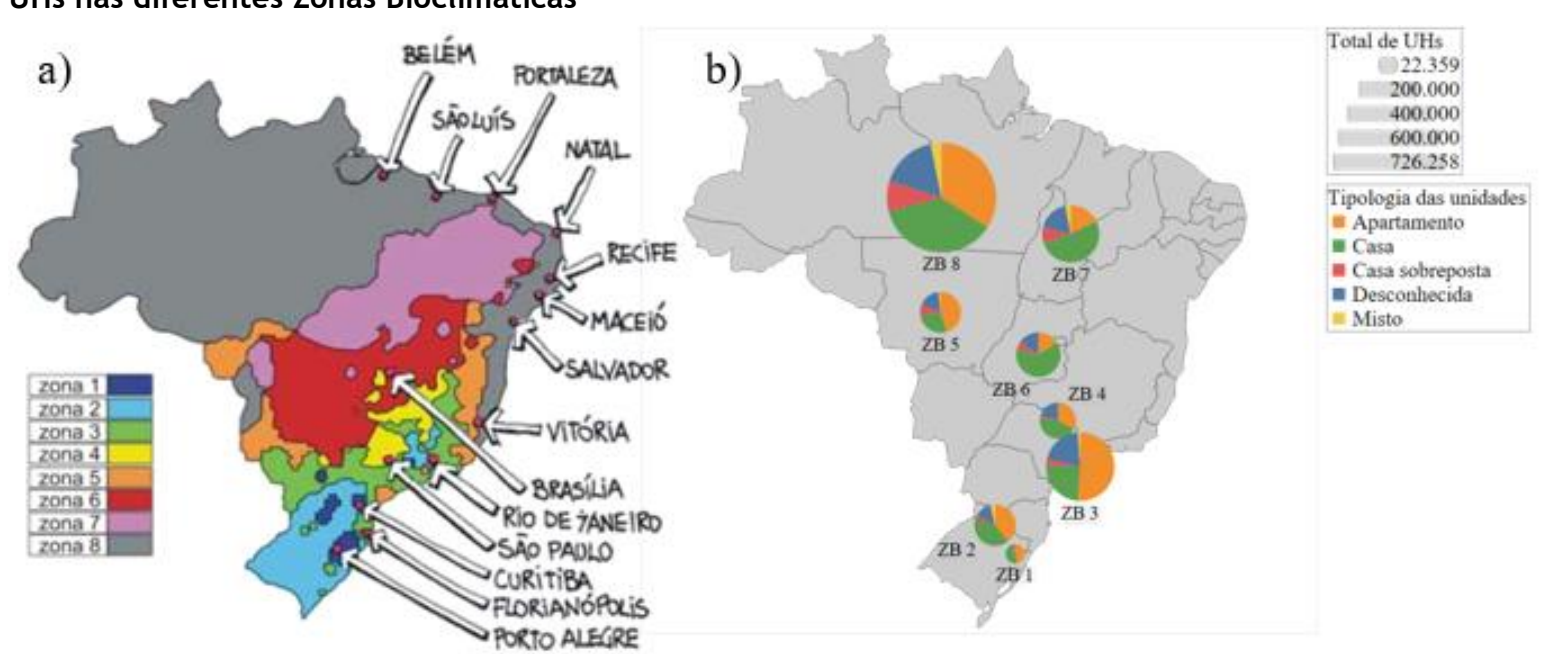

Fonte: (a) Lamberts, Dutra e Pereira (2014) e (b) adaptado de MDR (MINISTÉRIO..., 2020). 


\section{Método de pesquisa}

A identificação dos parâmetros construtivos e de sistemas relevantes à eficiência energética em edificações foi realizada por meio de revisão sistemática de literatura, avaliando-se os artigos publicados nos últimos dez anos. Utilizou-se a base de dados Google Acadêmico para contemplar a literatura publicada em português, e a base de dados Scopus para incluir trabalhos nacionais publicados em bases internacionais. No Google Acadêmico, a pesquisa consistiu na inserção das palavras-chave "habitações de interesse social", "minha casa minha vida" e "eficiência energética", excluindo-se as palavras "urbano" e "urbanismo", uma vez que o enfoque deste estudo são as edificações. Ao todo, 199 estudos foram encontrados com a combinação das palavras-chave. Ao avaliar os documentos, 81 foram revisados para a determinação dos parâmetros mais relevantes à eficiência energética em HIS; os demais não foram avaliados por apenas mencionarem que alternativas de eficiência energética são importantes. No Scopus, utilizaram-se as palavras-chave "social hous*" ou "affordable hous*", "energy efficiency" e "Brazil". O asterisco corresponde ao operador booleano empregado para ampliar os resultados; nesse caso, todas as palavras começadas com "hous" são incluídas, por exemplo, house e housing. Nessa base de dados, estão disponíveis vinte artigos que se enquadram nas delimitações de palavras-chave e ano de publicação. Doze deles foram incluídos nessa revisão de literatura; os demais não tratam especificamente de alternativas de eficiência energética nas habitações e foram descartados.

A amostra total de artigos (93 publicações) foi utilizada para conduzir a revisão sistemática descritiva da literatura, que consistiu em determinar os aspectos apresentados como impactantes no desempenho energético de HIS brasileiras. De maneira geral, os trabalhos são dependentes de contextos específicos e aplicaram métodos variados: diferentes condições climáticas foram testadas, bem como realização de medições in loco, simulações computacionais ou avaliações prescritivas. Desta forma, o objetivo principal da revisão é sintetizar a literatura nacional referente a esse tópico a fim de descrever aspectos considerados impactantes à eficiência energética. Uma limitação do trabalho é resultante da diversidade dos métodos empregados nos estudos: cada trabalho avalia um aspecto ou um grupo específico de aspectos submetidos a condições climáticas também específicas. Portanto, é difícil estabelecer os aspectos mais ou menos impactantes ao se comparar todos os artigos; entretanto, ao término da revisão descritiva é apresentada uma síntese com a frequência dos termos, mostrando os aspectos mais estudados na literatura nacional. Ressaltase que ao se estabelecer critérios e palavras-chave para a realização de revisão sistemática da literatura, outros estudos podem ser realizados no futuro a fim de acompanhar os avanços na área. Nesse aspecto, outros pesquisadores podem repetir a busca sistemática (empregando as palavras-chave definidas neste artigo) a fim de verificar se novos aspectos serão apresentados pela comunidade científica nos próximos anos.

Os 93 documentos revisados foram elaborados em universidades brasileiras, e a nuvem de palavras apresentadas na Figura 5 mostra quais foram as instituições mais atuantes nessa área. As Figuras 6 e 7 sintetizam os anos e os tipos dos documentos revisados, respectivamente.

Figura 5 - Principais instituições relacionadas aos estudos revisados neste artigo

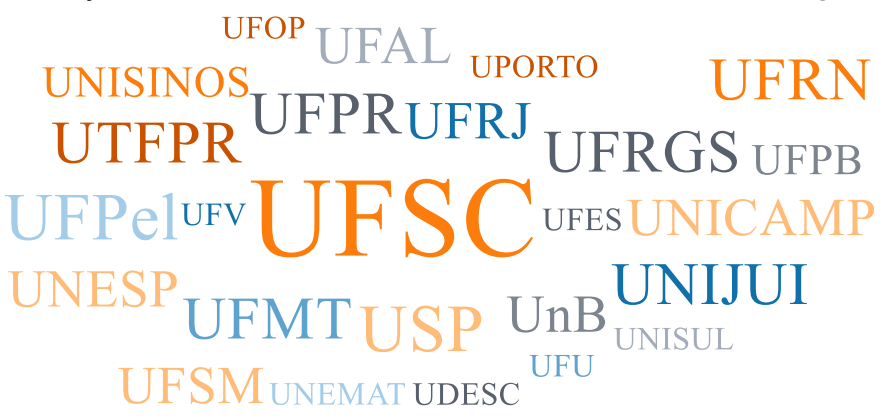


Figura 6 - Histórico de elaboração de estudos sobre eficiência energética em habitações de interesse social

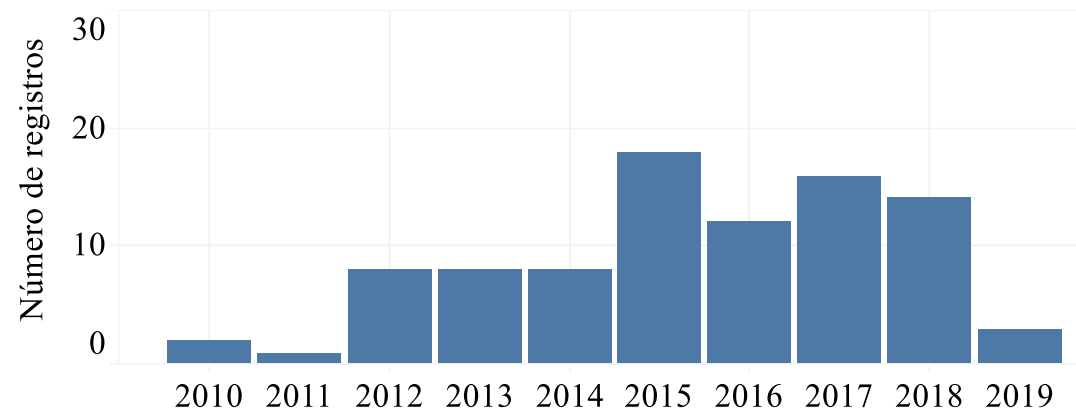

Ano da publicação

Figura 7 - Documentos utilizados nessa revisão de literatura

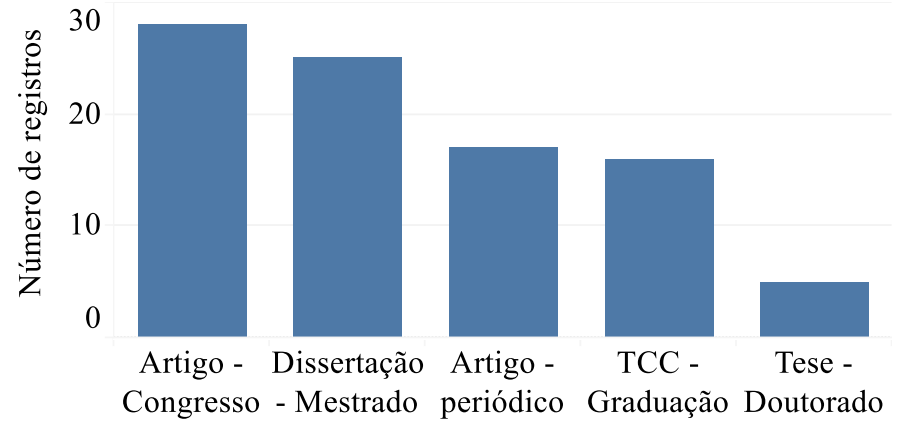

\section{Aspectos impactantes no desempenho energético de HIS brasileiras}

Nesta seção são sintetizados os aspectos apresentados na literatura como impactantes à eficiência energética em edificações. Ressalta-se que, pela diversidade de abordagens, este trabalho não aponta quais são os aspectos mais ou menos impactantes, tendo em vista as diversas condicionantes dos resultados, como diferenças nos métodos aplicados ou diferenças nas combinações de parâmetros testados. Entretanto, a sólida base nacional de estudos relacionados à eficiência energética de HIS justifica a necessidade de se considerar essas informações nos processos de projeto de edificações e também pode nortear futuros projetos de pesquisa nessa área.

\section{Área de abertura para iluminação e ventilação naturais}

As aberturas das habitações permitem aproveitar a iluminação natural e a ventilação natural. Consequentemente, o uso de diferentes esquadrias impacta nos percentuais úteis para condições de ventilação e iluminação. Nesse quesito, a literatura apresenta conclusões pontuais para diferentes climas brasileiros. Quando se considera o aproveitamento de iluminação natural, Quirino, Vaz e Leder (2017) concluíram que abertura de $30 \%$ em relação à área de piso é suficiente para a iluminação natural em cidades das ZBs 1, 3, 7 e 8. Entretanto, há divergências quanto às áreas ideais para ventilação natural. Enquanto Invidiata et al. (2016) indicam o uso de aberturas pequenas na ZB 1 para reduzir os níveis de ventilação, a literatura evidencia a importância da aplicação dessa estratégia em HIS localizadas em climas mais quentes (BATISTA et al., 2014; BRASILEIRO; MORGADO; LUZ, 2017; CECHINEL; HACKENBERG; TONDO, 2016; COSTA, 2011; MONTEIRO, 2012). Entretanto, os projetos devem ser elaborados cuidadosamente quanto ao uso demasiado de aberturas: Dantas (2015) concluiu que aumentar excessivamente as áreas de abertura pode piorar as condições térmicas de HIS na ZB 8, mesmo a ventilação natural sendo considerada uma importante estratégia nessa ZB (BATISTA et al., 2014). 
Apesar de impactantes no desempenho termoenergético de HIS, as habitações construídas nem sempre atendem áreas mínimas para as aberturas apresentadas na NBR 15220 (ABNT, 2005) - como evidenciado por Morgan (2014), que avaliou HIS na cidade de Campos Borges-RS (ZB 2). Adicionalmente, a literatura evidencia que além de critérios de áreas mínimas de abertura, é importante propiciar ventilação cruzada nas HIS (MARAFON, 2013). Nesse sentido, além do posicionamento ideal de aberturas em diferentes fachadas, a literatura também recomenda o uso de portas internas com frestas que favoreçam a ventilação natural mesmo estando fechadas (MORAIS, 2013).

Além de não atender aos requisitos relativos às aberturas, a literatura também evidencia que ampliações irregulares nas HIS comprometem as dinâmicas de aproveitamento de iluminação natural (SILVA; ALMEIDA; GHISI, 2017). Uma vez que as decisões dos moradores também impactam o desempenho das HIS, alternativas mais eficientes podem ser promovidas por meio de serviços de conscientização. O modo de operação das aberturas também pode afetar o desempenho das habitações devido ao impacto no aproveitamento de ventilação natural. Como exposto por Triana, Lamberts e Sassi (2016), a ventilação natural é um parâmetro de grande influência nas condições de conforto ambiental e de eficiência energética no Brasil. Portanto, garantir bons cenários para o uso de ventilação natural é de extrema importância tanto na atualidade quanto em cenários que consideram efeitos de mudanças climáticas (MONTES, 2016). Nesse aspecto, os usuários apresentam papel importante ao longo da vida útil das HIS: caso sejam mantidos os mesmos padrões de controle em locais com estações definidas (como a ZB 3), o desempenho das HIS pode ser desfavorável em uma das estações (BREITENBACH, 2015).

De maneira geral, a literatura apresenta informações contrastantes quanto ao aproveitamento de iluminação e ventilação naturais, pois está relacionado às áreas de abertura nas fachadas. Nesse aspecto, Leder e Oliveira (2015) e Santo (2014) apresentam o sistema misto de veneziana e vidro e o uso de janelas com persianas integradas, respectivamente, como alternativas eficientes para melhorar os níveis de iluminação e ventilação das habitações. Por fim, a literatura também aborda a infiltração de ar, que está relacionada ao tipo de esquadria empregada. Tubelo et al. (2018) mostraram que, ao se limitar a infiltração de ar, as temperaturas internas foram aumentadas durante o inverno e as temperaturas de pico foram reduzidas durante o verão resultados considerados positivos em relação aos níveis de conforto dos usuários.

\section{Orientação solar}

As orientações das fachadas dos ambientes de permanência prolongada (quartos e salas) são importantes para avaliar os níveis de eficiência energética das UHs, uma vez que a radiação solar recebida em cada fachada contribui para o aquecimento dos ambientes internos e, principalmente nos climas mais quentes, pode resultar em consumo com condicionamento mecânico. Alves, Pedrini e Lima (2012) e Brasileiro, Morgado e Luz (2017) avaliaram as equações do método prescritivo do Regulamento Técnico da Qualidade para o Nível de Eficiência Energética de Edificações Residenciais (RTQ-R) e concluíram que a orientação solar das edificações é bastante significativa, uma vez que as fachadas com incidência de radiação solar têm influência nos níveis de eficiência energética da UH avaliada. Desta forma, a estratégia adotada por Monteiro (2012), de orientar as menores fachadas no sentido leste-oeste na ZB 8, favorece a obtenção de maiores níveis de eficiência energética, caso a habitação seja avaliada pelos critérios do RTQ-R. Apesar do grande impacto da radiação solar no desempenho das edificações, Morais (2013) indica que as orientações também devem ser observadas considerando-se os ventos predominantes do local.

Ao se utilizar simulações computacionais para avaliar o nível de eficiência energética de edificações, usualmente parte-se de estudos de casos de referência (base) aos quais são adicionadas estratégias para melhorias gradativas de desempenho energético. Alguns estudos demonstram que a orientação solar pode ser mais ou menos impactante de acordo com as estratégias combinadas. Barzan Neto (2018) mostra que a orientação é pouco significativa em edificações semelhantes com variações nos sistemas da cobertura. Entretanto, ao se incluir variações nas paredes e aberturas, a orientação se torna mais influente no desempenho termoenergético das habitações. Algumas medidas de eficiência energética também podem ser consideradas sem levar em conta a orientação - como a redução da absortância da cobertura. Dörfler e 
Krüger (2014) indicam que a combinação entre orientação e dimensões das áreas envidraçadas impacta significativamente no desempenho das edificações da ZB 1, onde as maiores necessidades são de aquecimento. Essa informação também é válida para habitações construídas em climas mais quentes, onde a combinação de grandes aberturas em orientações com maiores níveis de radiação solar resulta em desempenho insatisfatório. Rodrigues, Oliveira e Carlo (2015) avaliam que quando se considera pavimentostipo de edificações multifamiliares, a influência da orientação é ainda mais evidente. Nesse cenário, os efeitos da troca de calor com o solo e com a cobertura são neutralizados e as paredes são as maiores responsáveis pelas trocas térmicas com o meio externo.

Tendo em vista que o impacto da orientação solar está condicionado a outros parâmetros da envoltória das HIS, o método empregado por Dörfler e Krüger (2016), que avaliaram por meio de simulações computacionais a influência de oito orientações solares no desempenho das habitações, resulta em estratégias de projeto adequadas ao local estudado. Os autores avaliaram as cidades de Curitiba-PR, São Paulo-SP, Picos-PI e Recife-PE; ressaltando que outros municípios podem se beneficiar de estudos similares.

\section{Tipologia do imóvel}

A tipologia das habitações (uni ou multifamiliares) é importante para determinar as condições da envoltória, o autossombreamento das fachadas e o desempenho da ventilação natural, por exemplo. A revisão de literatura apontou que as condições de contorno (contato com o solo e/ou cobertura ou nenhum contato) impactam o desempenho das edificações. Em especial, destaca-se que nas UHs de edificações multifamiliares em contato com o solo, as trocas de calor entre o ambiente interior e o solo podem favorecer a redução da temperatura dos ambientes. O oposto pode ocorrer em UHs localizadas na cobertura, pois estão expostas diretamente à incidência de radiação solar e poderão ter os ambientes internos superaquecidos.

Rodrigues, Oliveira e Carlo (2015) e Veiga (2018) evidenciaram que os apartamentos da cobertura apresentam as piores condições de desempenho em habitações multifamiliares, enquanto os apartamentos térreos apresentam os melhores níveis de desempenho. Como o desempenho das HIS está relacionado à tipologia das mesmas, é importante que as habitações sejam modeladas corretamente nas simulações computacionais de forma a propor estratégias bioclimáticas ou obter certificações de qualidade ambiental. Diante do exposto, Oliveira et al. (2012) evidenciaram a importância de integrar corretamente a temperatura do solo nas simulações computacionais de HIS térreas. Além disso, os autores concluíram que, quanto mais isolada for a habitação, mais impactante é a influência da temperatura do solo. Desta forma, a tipologia das HIS também apresenta impactos condicionados às demais características da envoltória. Determinar o impacto de diversas combinações em diferentes climas é importante tanto para se compreender as dinâmicas das HIS já construídas quanto para propor estratégias de projeto às futuras edificações.

\section{Cobertura}

A revisão de literatura indicou grande influência das propriedades termofísicas da cobertura no desempenho termoenergético das habitações. Capacidade térmica, absortância solar, atraso térmico, transmitância térmica e emissividade foram indicados como fatores significativos. Destaca-se que a designação dos sistemas utilizados nas UHs construídas é suficiente para determinar todas as propriedades a partir do método de cálculo da NBR 15220 (ABNT, 2005). Então, o levantamento dos materiais que compõem o sistema é suficiente para estimar sua influência no desempenho da UH, o que evidencia a importância da documentação dessas habitações para que diferentes profissionais tenham acesso às informações.

A absortância solar da cobertura foi listada como um dos parâmetros mais influentes no desempenho de habitações pelo método do RTQ-R (SILVA; GHISI, 2013); portanto, reduzir seus valores absolutos impacta positivamente nas equações do método prescritivo do regulamento (ALVES; PEDRINI; LIMA, 2012). Essa estratégia é importante tanto em climas moderados, como os da ZB 3 (BREITENBACH, 2015), quanto em climas mais quentes, como os da ZB 7 (RIOS, 2015; RIOS et al., 2017) ou ZB 8 (LIMA; PEDRINI; 
ALVES, 2012). A absortância solar, que está relacionada à cor escolhida para a cobertura, pode ser considerada pelos projetistas a fim de melhorar o desempenho termoenergético de HIS. A literatura evidencia que, além da cor, as propriedades dos materiais empregados na construção civil também podem influenciar os níveis de radiação solar absorvidos. Nesse sentido, Pereira, Ghisi e Güths (2014) mostraram que, comparando-se elementos brancos, aqueles revestidos com tintas especiais de alta refletância no infravermelho são ainda mais eficazes para reduzir a absorção solar e melhorar o desempenho das habitações em regiões de clima quente.

Quando combinadas a menores níveis de transmitância térmica, as baixas absortâncias solares impactam ainda mais o desempenho das habitações (BODACH; HAMHABER, 2010). Triana e Lamberts (2013) concluíram que o uso de cobertura com isolamento e baixa absortância teve resultado mais satisfatório em relação a maiores níveis de ventilação natural na ZB 3. Aprofundando-se mais no assunto, Triana, Lamberts e Sassi (2018) concluíram que essas estratégias também são eficazes considerando-se cenários climáticos futuros. Além de estratégias utilizando a ventilação natural, sistemas de cobertura adequados são estratégias de fácil implementação em HIS. Em reformas, essa opção seria menos onerosa em comparação à troca de esquadrias. Outra alternativa de simples instalação é o uso de mantas térmicas de alumínio com o intuito de reduzir a emissividade térmica das coberturas. Essa estratégia foi apresentada por Moreno, Morais e Souza (2017) como uma alternativa viável para todas as oito ZBs testadas. O uso de coberturas isoladas também se mostrou viável para a ZB 5 (MARAFON, 2013) e para as ZBs 7 e 8 (MONTEIRO, 2012; RODRIGUES; OLIVEIRA, CARLO, 2015). Além disso, Veiga (2018) afirma que, dadas as condições de contorno das habitações, a influência da cobertura no desempenho térmico e energético é significativa. Em apartamentos de cobertura em habitações multifamiliares, por exemplo, variações no sistema de cobertura da edificação geram grandes impactos no desempenho das habitações. Adicionalmente às baixas absortâncias e transmitâncias, a literatura também evidencia que o uso de materiais menos frequentes em HIS também impacta positivamente seu desempenho termoenergético. Jaudy et al. (2015) e Caldeira, Sposto e Caldas (2016) apontam que o uso de barreiras radiantes de alumínio e telhas termoacústicas podem melhorar o desempenho das HIS.

\section{Paredes}

De maneira similar às coberturas, as propriedades termofísicas das paredes são impactantes no desempenho das HIS. As paredes devem seguir indicadores mínimos de desempenho para garantir maiores níveis de eficiência energética das habitações. Portanto, conhecer as características dos sistemas construtivos utilizados permite a determinação das propriedades dos materiais pelo método da NBR 15220 (ABNT, 2005).

A redução da absortância solar da parede é significativa nas equações do método prescritivo do RTQ-R (ALVES; PEDRINI; LIMA, 2012). Desta forma, pode favorecer o desempenho de habitações tanto em climas mais amenos, como os da ZB 3 (BREITENBACH, 2015), quanto em climas mais quentes, como os da ZB 7 (RIOS, 2015) ou ZB 8 (BRASILEIRO; MORGADO; LUZ, 2017; TRIANA; LAMBERTS; SASSI, 2015). Além das absortâncias, as transmitâncias térmicas também são expressivas no desempenho de edificações em diferentes ZBs, como mostraram Cruz et al. (2014), que avaliaram cidades das ZBs 3 e 8; Tubelo et al. (2018), que avaliaram cidades das ZBs 1 e 3; e Dalbem et al. (2019), que avaliaram as ZBs 1, 2 e 3. Além disso, Triana, Lamberts e Sassi (2018) concluíram que a utilização de composições com menores transmitâncias térmicas nas paredes é viável considerando-se cenários climáticos futuros. De acordo com Guarda et al. (2018), o aumento da camada de reboco das paredes melhora o desempenho das HIS nas ZBs de Mato Grosso (5, 6 e 7). É importante verificar que, em alguns casos, como avaliado por Marafon (2013), UHs do PMCMV no interior do Mato Grosso não cumprem requisitos mínimos quanto à transmitância das paredes. A autora encontrou variação entre os acabamentos de habitações para diferentes faixas de renda, sendo que nas habitações dos moradores com renda máxima de um salário mínimo, não se verificou argamassa interna nas paredes, e revestimento externo completo apenas na fachada principal. A ausência 
desses revestimentos impede que as paredes atinjam os níveis mínimos de transmitância térmica exigidos pela NBR 15575 (ABNT, 2013).

Além disso, nas regiões brasileiras com estações climáticas bem definidas, existe preocupação quanto ao atendimento de requisitos durante uma estação e descumprimento durante outra. Nesse sentido, absortâncias solares mais altas são sugeridas para a ZB 1 (INVIDIATA; GHISI, 2016) e para a ZB 2 (OLIVEIRA; SILVA; PINTO, 2014); ao contrário de locais com climas mais quentes, onde se indica o uso de baixas absortâncias solares. De maneira similar, os níveis de transmitância térmica recomendados também são condicionados aos climas locais. Consequentemente, diferentes sistemas construtivos podem ser inadequados em determinadas cidades. Eli (2018) concluiu que, apesar de viável para o clima de São Paulo (ZB 3), o uso de isolamento térmico nas paredes não é adequado para Salvador (ZB 8); de maneira similar, Dalbem et al. (2017) e Brenner (2017) apontam que materiais isolantes nas paredes são vantajosos nas ZBs 1 e 2, respectivamente. Ainda quanto aos sistemas construtivos, a literatura apresenta diversas críticas em relação ao uso de paredes de concreto nas HIS brasileiras. O uso de paredes de concreto se mostrou ineficiente na ZB 3 (MORAGA, 2017) e na ZB 4 (ALVARES, 2018; BRAGA, 2018). Carvalho (2012) concluiu que paredes de concreto, apesar de minimamente satisfatórias durante o verão, são insatisfatórias durante o inverno na ZB 2. Ao comparar todas as ZBs, Ferreira e Pereira (2012) concluíram que paredes de concreto são mais viáveis nos climas mais frios, uma vez que são muito insatisfatórias nos climas mais quentes (ZBs 7 e 8). Também ao comparar todas as ZBs, Moreno, Morais, Souza (2017) concluíram que os piores desempenhos térmicos foram obtidos ao se utilizar paredes de concreto, e indicam que o uso de blocos cerâmicos é mais apropriado. Além de fatores como absortância solar e transmitância térmica, Pereira e Ghisi (2011) concluíram que os níveis de capacidade térmica e atraso térmico impactam no desempenho de habitações, influenciando no conforto térmico dos usuários durante a operação.

De maneira geral, a literatura enfatiza a influência das paredes no desempenho termoenergético das HIS. Palacio (2013) classificou as alvenarias de vedação como um dos componentes de maior impacto ambiental nas HIS, tanto pelos materiais quanto pelo consumo de energia. Materiais menos utilizados no cenário da construção civil brasileira, como paredes externas de gesso, são apresentados na literatura como alternativa para a rápida construção de HIS sem comprometer o desempenho das mesmas (PAULA, 2017). Componentes construtivos sustentáveis ou ecológicos, como paredes de adobe, também são apresentados na literatura para reduzir o impacto ambiental das HIS (AZEVEDO, 2018). De maneira similar, o uso de sistemas construtivos de madeira se mostrou mais viável em relação ao desempenho da envoltória quando comparado a paredes de blocos de concreto (VALDENEBRO; DIETRICH; INO, 2019). Os autores também concluíram que os materiais empregados no isolamento térmico das paredes podem ser provenientes de madeira: placas de fibras de madeira mineralizada resultaram em melhores desempenhos do que placas de EPS (Poliestireno Expandido). Quanto a alternativas ecológicas, Carvalho (2018) concluiu que, por serem desconhecidas pelos moradores, a manutenção ao longo da vida útil da habitação pode ficar comprometida. Desta forma, além de utilizar componentes inovadores e ecológicos, ressalta-se que os profissionais responsáveis pelos avanços no cenário de HIS nacional devem apresentar alternativas para disseminar o conhecimento desses sistemas aos futuros usuários. Uma maneira de consolidar essa prática no mercado da construção civil nacional é a elaboração de eco-labeling para os materiais empregados na construção civil, como proposto por Bodach e Hamhaber (2010).

\section{Sombreamento}

Sombreamento é uma estratégia adequada para várias zonas bioclimáticas: Eli (2018) concluiu que esta é uma alternativa viável tanto para a ZB 3 quanto para a ZB 8. Entretanto, é evidente que o uso de sombreamento é ainda mais efetivo nos climas mais quentes do Brasil, afinal, ao se sombrear uma edificação, o ganho de calor por meio de radiação solar é reduzido e o desempenho da envoltória é otimizado. Nesse sentido, Costa (2011) evidenciou a importância do uso de sombreamento em cidades da ZB 8, e Dantas (2015) concluiu que o sombreamento pode ser mais eficaz do que o aumento excessivo das aberturas para ventilação nessa ZB. O uso de sombreamento nas aberturas foi apresentado por Triana, 
Lamberts e Sassi (2018) como uma estratégia importante para garantir bons níveis de desempenho energético de HIS considerando-se cenários climáticos futuros. Além do clima, as condições de contorno das habitações também influenciam o desempenho dos sistemas de sombreamento: Veiga (2018) mostrou que, em pavimentos-tipo, o uso de sombreamentos nas aberturas é mais influente em comparação a casos com outras condições de contorno. Essa relação é devida ao impacto que as paredes e aberturas têm nesse cenário, uma vez que a influência do solo e da cobertura é minimizada.

$\mathrm{O}$ uso de beirais é frequente nas HIS térreas, e essa característica pode favorecer o sombreamento das aberturas e melhorar o desempenho termoenergético das HIS (MARAFON, 2013). Entretanto, a literatura evidencia problemas com as dimensões dos beirais: Monteiro (2012) concluiu que algumas edificações do PMCMV apresentam beirais com menos de $30 \mathrm{~cm}$, o que dificulta o sombreamento da envoltória. Além de beirais largos, o sombreamento das HIS pode ser oriundo de venezianas, brises-soleil, partes da própria edificação (autossombreamento) ou arborização do entorno. Triana e Lamberts (2013) apresentaram um projeto de uma edificação que considera estratégias passivas, como a inclusão de varandas e paisagismo como estratégia de sombreamento para as habitações, além de incluir venezianas nos ambientes de permanência prolongada. Possani (2015) apresentou proposta para arborizar os entornos das habitações do PMCMV a fim de criar microclimas que propiciam melhor desempenho às habitações. Finalmente, apesar de menos efetivos do que os sombreamentos externos (que protegem da radiação solar antes de incidir no interior das habitações), Mota e Cunha (2016) também classificam os sombreamentos internos (e.g., cortinas) como efetivos para melhorar o desempenho das HIS. Nesse sentido, persianas integradas nas aberturas também foram apresentadas na literatura como dispositivos significativos (INVIDIATA; GHISI, 2016).

Dada a importância dos sistemas de sombreamento no desempenho das HIS, recomenda-se que os projetos dessas habitações priorizem estratégias de sombreamento no futuro. Para as habitações já construídas que apresentam problemas quanto ao desempenho térmico, Cechinel, Hackenberg e Tondo (2016) evidenciam a possibilidade de instalar brises-soleil durante a operação das edificações. Essa medida de eficiência energética pode ser utilizada em alternativas de retrofit energético.

\section{Dimensionamento do quadro de cargas}

Apesar da difícil avaliação em estudos de campo, ressalta-se a necessidade de criar critérios específicos para que os projetistas considerem da maneira mais real possível as necessidades do sistema durante a fase de uso das edificações. Em pesquisa de campo realizada em Campos Borges-RS, Morgan (2014) constatou que há grande variação na posse de equipamentos das famílias de nove unidades habitacionais avaliadas. A desconsideração de alguns equipamentos durante o projeto pode sobrecarregar o sistema na fase de operação. Além disso, Alvaristo et al. (2015) também indicam a necessidade de orientar os moradores das edificações quanto à instalação de novas cargas para que um circuito não seja sobrecarregado em relação a outro, evitando a dissipação excessiva de energia. $\mathrm{O}$ fator da dimensão humana relativo ao consumo energético é evidenciado e tem sua importância combinada com os sistemas das habitações. É importante conhecer as necessidades dos usuários para que os projetos contemplem diferentes aspectos relevantes durante a vida útil das habitações, assim como ressalta-se a necessidade de conscientização dos usuários quanto ao consumo energético de suas habitações.

\section{Selo Casa Azul}

Conhecer as habitações que foram certificadas com o "Selo Casa Azul" é uma medida importante para avaliar os critérios específicos de eficiência energética em diferentes localidades. A criação de bancos de dados com informações variadas sobre o desempenho das unidades habitacionais favoreceria $o$ desenvolvimento de estudos e políticas públicas em relação à eficiência energética das HIS. Entretanto, nos estudos de caso revisados nesse artigo, não foram encontrados empreendimentos que receberam o Selo em questão. A literatura apresenta condomínios que, mesmo cumprindo alguns critérios exigidos pelo Selo Casa Azul, não cumprem todas as exigências para obter o Selo: Assentamento Margem Esquerda em Gaspar-SC 
(SILVA, 2012); Loteamento Auxiliadora II em Santa Rosa-SP (ANGELONI et al., 2018); Residencial Bairro Carioca em Triagem, Rio de Janeiro-RJ (PROVENZANO; BASTOS, 2017); Residencial Leonel Brizola em Santa Maria-RS (CONTO, 2017); Conjunto Habitacional Zorilda em Suzano-SP (XIMENES; TEIXEIRA, 2016); além de alguns condomínios avaliados em Porto Alegre (FROENER, 2013), CriciúmaSC (SILVA, 2016) e na região metropolitana de Curitiba (FORTUNATO, 2014).

Froener (2013), comparando o custo entre habitações que não consideram aspectos do "Selo Casa Azul" e habitações adequadas a esses critérios, concluiu que a construção direta das habitações avaliadas seria 1,07\% mais onerosa caso as soluções consideradas viáveis e adequadas aos empreendimentos fossem realizadas. A obtenção do Selo depende da adoção de objetivos formais por parte das equipes envolvidas. A obrigatoriedade desse Selo para habitações do PMCMV poderia representar avanços em relação às condições atuais das habitações já construídas. Porém, a falta de informação por parte de profissionais responsáveis pelos projetos, somada à falta de incentivos de outros componentes da cadeia produtiva da indústria da construção civil, são fatores limitadores para a aceitação do Selo Casa Azul (CASTRO FILHO, 2013).

\section{Aquecimento solar de água}

Além de ser um dos critérios do Selo Casa Azul, o aquecimento solar de água reduz o consumo energético com o uso dos chuveiros elétricos. Nos estudos de Montes (2016) e Giglio, Santos e Lamberts (2019), o uso de aquecimento solar de água se mostrou viável, principalmente em casas unifamiliares da ZB 3. As conclusões de Giglio, Santos e Lamberts (2019) enfatizam a possibilidade de reduzir a demanda de pico ao se substituir chuveiros elétricos por sistemas de aquecimento solar. Barzan Neto (2018) avaliou o impacto de diferentes sistemas de aquecimento de água em habitações de interesse social na ZB 3 e concluiu que o uso de aquecedores solares permitiu que a edificação avaliada obtivesse nível A de eficiência energética de acordo com os critérios do RTQ-R. Breitenbach (2015) concluiu que o aquecimento solar de água elevou em um nível a classificação da eficiência energética pelo método do RTQ-R na ZB 3. Coelho e Marcon (2017) citam a importância do uso de aquecimento solar de água na ZB 2 e sugerem a elaboração do aquecedor de baixo custo desenvolvido pela CELESC (CENTRAIS..., 2009) dentro dos próprios edifícios residenciais de interesse social. Braga, Gabriel e Mozena (2016) afirmam que, além de ser uma alternativa renovável e limpa à matriz energética nacional, o uso de aquecimento solar impacta positivamente na autonomia do acesso de energia e qualidade de vida de famílias de baixa renda. Entretanto, a literatura evidencia as dificuldades em relação ao dimensionamento correto dos sistemas de aquecimento de água. Lima, Prado e Taborianski (2006) afirmam que a maioria dos sistemas são dimensionados de acordo com tabelas dos fabricantes, tendo pouca informação em relação a dados científicos. Os autores elaboraram um método de dimensionamento baseado em simulações numéricas que pode ser aplicado para dimensionar os sistemas de maneira mais precisa.

Affeldt (2015) realizou avaliações em campo com moradores de habitações do PMCMV e concluiu que $88 \%$ deles estão insatisfeitos com a eficiência energética de seu imóvel. Como alternativa, o autor sugere a instalação de aquecedores solares. Essa alternativa, além de reduzir o consumo energético, pode aumentar o nível de satisfação dos moradores. Entretanto, apesar de vantajoso, é necessário que os sistemas de aquecimento solar sejam projetados e executados adequadamente. Em avaliações de campo na cidade de Santa Rosa-RS, Vier et al. (2015) concluíram que a maioria dos moradores não perceberam redução em suas faturas mensais. Isto é, a instalação de um sistema com o intuito de reduzir o consumo de energia nas habitações e aumentar o nível de satisfação de seus moradores não garante que esses resultados sejam alcançados. É necessário, portanto, aprofundar as avaliações quanto a esses aspectos, assim como propor orientações aos moradores quanto ao uso correto dos sistemas. Além do aquecimento solar, o uso racional de água em HIS está relacionado à conservação de energia: Vieira (2012) mostrou que o aproveitamento de água cinza aliado à instalação de equipamentos economizadores apresenta potencial de conservação de energia quando se considera a escala urbana. 
Aliado à redução de consumo energético proporcionada pelo uso de aquecimento solar, o consumo eficiente de água também é apresentado na literatura como uma medida para melhorar o desempenho das HIS. Nesse aspecto, Ghisi et al. (2015b) apresentam o uso de fontes alternativas de água, bem como o uso de equipamentos economizadores, como alternativas viáveis. Os autores ressaltam que os resultados obtidos podem facilitar a estimativa de consumo para novos empreendimentos, melhorando as estratégias para gestão da água no município, além de facilitar a realização de campanhas de conscientização para os moradores dessas habitações. A literatura também evidencia o nexo água-energia, enfatizando que a redução no consumo de água pode ter consequente redução no consumo de energia nos sistemas de distribuição de água e tratamento de esgoto. Vieira e Ghisi (2016) utilizaram HIS como estudo de caso e concluíram que melhorar a gestão de água nessas habitações (considerando o uso de equipamentos economizadores) pode reduzir a produção de esgoto e, consequentemente, reduzir a energia embutida nas estações de tratamento.

\section{Dimensão humana relacionada ao consumo energético em HIS}

De modo similar aos avanços na literatura internacional quanto ao reconhecimento sobre o impacto da dimensão humana no desempenho das edificações, a literatura nacional também evidencia a relação entre o desempenho das HIS e o comportamento, expectativas e/ou necessidades de seus usuários. Ao evidenciar essa relação, também se torna evidente a possibilidade de tornar as edificações mais eficientes ao se incluir essa preocupação na fase de projeto (design centrado nos usuários) e na fase de operação das edificações (programas de conscientização dos usuários).

Balvedi et al. (2018) determinaram padrões de comportamento de usuários para serem incluídos em simulações computacionais. A ocupação foi o parâmetro que mais impactou o desempenho das habitações, evidenciando a influência das rotinas dos moradores nos consumos energéticos de suas residências. Ghisi et al. (2015a) avaliaram rotinas de ocupação e operação de aberturas e equipamentos em HIS; os resultados apresentados podem melhorar as práticas de simulação computacional dessa tipologia. Ocupação e comportamento dos usuários também foram classificados como impactantes por Mota et al. (2015). No trabalho de Daros (2013), os hábitos de consumo dos moradores de HIS foram analisados para elaborar alternativas sustentáveis em relação ao consumo de água e energia para higienização de roupas. Esse tipo de abordagem pode atender necessidades de edificações isoladas, assim como necessidades mais amplas, de uma comunidade. Ressalta-se que, com abordagens similares, projetos de habitações centrados nos usuários podem ser elaborados.

Para se conhecer fatores relacionados à dimensão humana do consumo energético em edificações, diferentes métodos qualitativos podem ser empregados. Além de questionários, como os empregados por Balvedi et al. (2018), avaliações pós-ocupação (APO) podem ser valiosas nas HIS nacionais. A partir de APO, informações quanto às características construtivas e qualidade da execução das habitações também podem ser levantadas, bem como os impactos dessas condições na satisfação de seus moradores. A literatura engloba o trabalho de Garcia (2015), que aplicou APO em Santos-SP com enfoque em desempenho e conforto térmico dos moradores. Entretanto, como exposto por Samarago et al. (2016), a aplicação dessas avaliações também permite conhecer as necessidades dos usuários de HIS, o que pode resultar em melhorias nos projetos de futuras habitações com práticas de design centrado no usuário.

Considerando-se critérios de design centrado nos usuários, Aragão e Hirota (2016) sintetizaram os requisitos de usuários de habitações do PMCMV quanto as suas habitações e concluíram que, dentre os 22 tópicos elencados, o terceiro no índice geral de importância é "gastar menos com as contas de água, luz, outros". Assim, a obtenção de edificações energeticamente eficientes é, além de uma política pública que visa à sustentabilidade, uma forma de tornar os moradores do PMCMV mais satisfeitos com seus lares. No entanto, há de se esclarecer questões técnicas relativas ao consumo de energia. Como foi exposto por Santos, Volpato e Koop (2015), a maioria dos moradores de HIS em Curitiba que participaram da pesquisa de campo desconhecem as lâmpadas LED, e 95\% deles apontam as lâmpadas fluorescentes como as mais econômicas. Conto (2017) realizou um estudo em Santa Maria-RS e verificou a existência de lâmpadas incandescentes nas habitações, mesmo após a proibição de sua venda. Em relação aos sistemas de iluminação, conhecer as 
necessidades dos usuários pode favorecer a criação de protótipos de iluminação centrados nos usuários, como proposto por Serbena (2013). Além disso, propostas de retrofit, como a de Tsuruda et al. (2017), podem garantir a troca de sistemas insatisfatórios do ponto de vista energético respeitando as preferências dos usuários.

Além de considerar as necessidades dos moradores ainda na fase de projeto, é imprescindível que os usuários sejam informados quanto ao funcionamento dos sistemas de suas residências para que as edificações apresentem desempenho satisfatório na fase de operação. Miyazato (2012) expõe a importância de conhecer os hábitos e as necessidades dos usuários para otimizar o funcionamento de sistemas de aquecimento solar, uma vez que os limites de operação dos sistemas devem ser respeitados. Giglio (2015) constatou que muitos usuários relataram falta de conhecimento quanto ao funcionamento de seus chuveiros com aquecimento solar. Uma vez que a relação entre os usuários e a forma com que eles se apropriam das tecnologias está ligada ao desempenho dos sistemas, é importante que haja conscientização e, até mesmo, treinamento dos usuários quanto ao funcionamento desses sistemas nas habitações. Nesse âmbito, Ribeiro (2010) concluiu que, ao envolver a comunidade na montagem e instalação de aquecedores solares, os usuários se apropriaram melhor da tecnologia, o que impacta positivamente em mudanças de hábitos durante a operação.

\section{Discussões}

A principal contribuição dessa revisão de literatura é apresentar uma síntese dos aspectos impactantes no desempenho energético de HIS brasileiras a diferentes partes interessadas (Figura 8). A partir da identificação desses parâmetros, diferentes profissionais podem melhorar suas práticas: pesquisadores podem embasar seus estudos nos aspectos apresentados, projetistas podem incluir critérios de eficiência energética e de design centrado no usuário em suas práticas, assim como responsáveis por políticas públicas podem incluir critérios de avaliação das edificações à aprovação de futuros empreendimentos. Ao longo dessa seção são apresentados os desafios e oportunidades em relação à eficiência energética de HIS, critérios que basearam a proposição de um protocolo de avaliação de unidades habitacionais construídas considerando-se a síntese dos aspectos impactantes.

\section{Desafios e limitações em pesquisas relacionadas a HIS brasileiras}

Na bibliografia relacionada à habitação social no Brasil, evidencia-se a dificuldade no levantamento de dados das habitações construídas. Esses parâmetros poderiam ser informados diretamente pelas construtoras e/ou pelas Instituições Financeiras e facilitariam tanto o estudo das habitações construídas quanto a proposição de melhorias. Conforme apresentado por Lohmann (2015) - que avaliou as condições de HIS de caráter permanente construídas após os desastres naturais no Vale do Itajaí, em 2008 - uma alternativa importante é a elaboração de bancos de dados das soluções de projeto das habitações e dos assentamentos a fim de melhorar a condição de futuras habitações. Ampliando-se o escopo do trabalho, criar bancos de dados nacionais com informações detalhadas sobre as HIS construídas ajudaria diferentes partes interessadas nesse cenário. Além de informar a população quanto à qualidade e às características das habitações entregues, essa estratégia facilitaria estudos na área de eficiência energética. Nesse aspecto, a obtenção de grande volume de dados proporcionaria a execução de benchmarking energético desta tipologia a fim de conhecer os principais aspectos que afetam o desempenho das HIS nacionais. 
Figura 8 - Aspectos apresentados nessa revisão destacados no logotipo do PMCMV

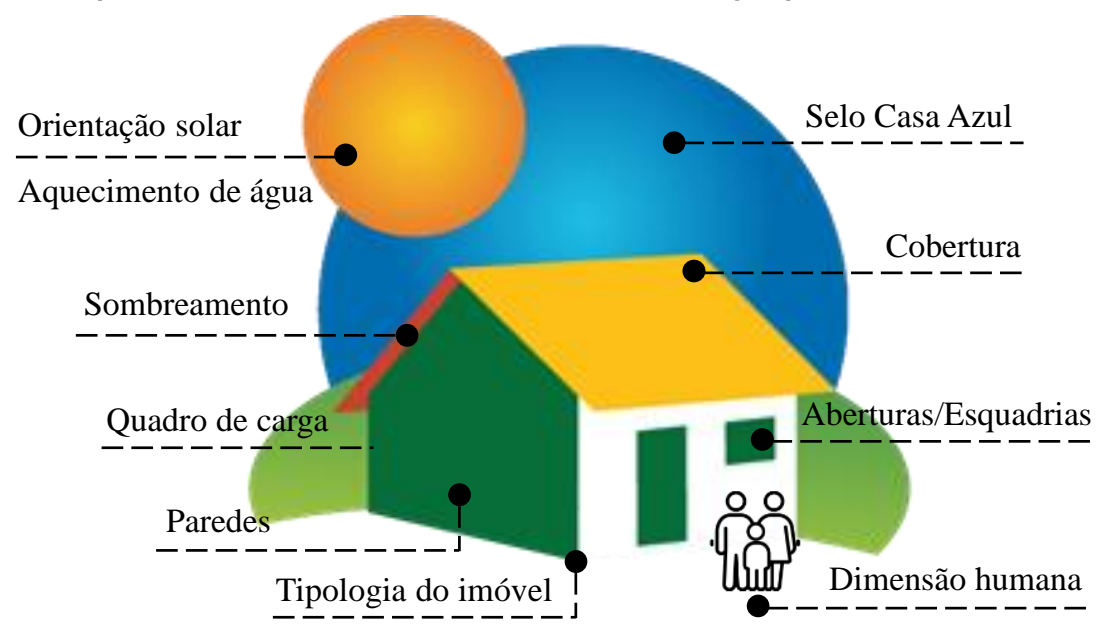

Além da dificuldade quanto à obtenção de dados, a literatura também evidencia obstáculos em relação ao projeto dessas edificações. Em relação à eficiência energética, a aplicação de simulação computacional pode aprimorar os processos de projeto de edificações, uma vez que melhores alternativas à construção podem ser obtidas. Entretanto, o uso de simulação computacional nas fases iniciais de projeto ainda precisa de atenção. Silva et al. (2017) concluíram que incertezas físicas podem impactar os níveis de desempenho térmico de habitações residenciais determinados por meio de simulação computacional. Fatores como absortância solar da cobertura e propriedades termofísicas da argamassa e de revestimento cerâmico das envoltórias foram listados como impactantes na determinação de valores de graus-hora. Desta forma, um dos desafios está relacionado à obtenção de valores mais precisos, tanto por meio de bases de dados mais confiáveis quanto por meio de medições. De maneira similar, a modelagem das edificações (SILVA; GHISI, 2014a) e a consideração de padrões de comportamento dos usuários (SILVA; GHISI, 2014b) em simulações computacionais também representam fontes de incerteza. Além disso, outro desafio em simulações computacionais de desempenho térmico e energético de HIS é a avaliação da energia embutida nas edificações sob diferentes estratégias considerando-se o ciclo de vida das habitações. Nesse sentido, Invidiata e Ghisi (2016) avaliaram o impacto de diferentes tipos de sombreamento, e o método pode ser utilizado como base para avaliar outras estratégias que visam melhorar o desempenho termoenergético de HIS em diferentes climas.

Mesmo considerando-se as incertezas associadas às simulações computacionais, a inclusão dessas ferramentas nas práticas dos profissionais envolvidos é bastante importante e pode ser considerada como um desafio a ser aperfeiçoado. Desta forma, para facilitar a determinação do impacto de diferentes alternativas de projeto no desempenho de HIS, Anchieta (2016) elaborou um meta-modelo para realizar análises de regressão a partir de dados de simulações computacionais. Esses modelos apresentam, de maneira menos dispendiosa, os impactos de diferentes soluções de projeto. Ao se facilitar a obtenção de resultados, mais profissionais podem empregar ferramentas em suas práticas. Além de recorrer a alternativas complementares à simulação computacional, Gil (2017) evidenciou a possibilidade de simplificar as zonas térmicas para simular as HIS, o que permite maior adoção dessa prática.

Outro desafio para os estudos futuros é compreender de maneira mais consolidada a influência da dimensão humana relacionada ao consumo energético das HIS. Avaliações longitudinais por meio de questionários ou pesquisas de campo sobre posses e hábitos dos moradores podem esclarecer dúvidas quanto ao desempenho das edificações. Entretanto, o custo dessas avaliações pode ser elevado. Desta forma, alternativas como a criação de aplicativos para que os próprios moradores cadastrem informações sobre suas habitações pode viabilizar a coleta de grande volume de dados sobre o uso das HIS nacionais. Além disso, pesquisas já consolidadas como o Censo Nacional, que acontece a cada dez anos, também podem proporcionar informações importantes nessa área. 


\section{Oportunidades para melhorar as práticas referentes às HIS nacionais}

Apesar de não ser obrigatório, o cumprimento de requisitos do regulamento nacional de etiquetagem poderia ser incluído como critério de aprovação dos projetos de HIS. Como apresentado por Freire (2014), o descumprimento de requisitos da instrução normativa visando à eficiência energética de edificações afeta negativamente o desempenho das habitações. O desempenho insatisfatório, por sua vez, pode resultar em insatisfação de seus moradores e altos níveis de consumo energético. A utilização de alternativas sustentáveis nessas edificações também poderia ser incentivada. Como demonstrado por Ribeiro (2014), a inclusão de alternativas sustentáveis em HIS não representa, necessariamente, impactos negativos no orçamento dos projetos.

Realizar simulação computacional durante as etapas de projeto pode favorecer a determinação de estratégias adequadas para as habitações, bem como facilitar a obtenção de certificações energéticas. Nesse sentido, a utilização dos modelos de referência de HIS, apresentados por Triana, Lamberts e Sassi (2015) e por Ghisi et al. (2015c), pode favorecer a elaboração de projetos mais eficientes energeticamente, uma vez que permitem propor melhorias para os modelos que representam o estoque construído. Triana, Lamberts e Sassi (2015), utilizando dados baseados no censo de 2010, apresentaram modelos representativos para HIS uni e multifamiliares a partir de estatísticas descritivas (médias e modas) das características construtivas de habitações avaliadas. Ghisi et al. (2015c) determinaram, por meio de análises de agrupamento, modelos representativos tanto para a forma quanto para os materiais da envoltória das HIS a partir de dados obtidos em campo. Esses resultados fazem parte de um esforço coletivo realizado por pesquisadores de diferentes universidades brasileiras (UFSC, UFES, UFMS, UFS, UFPR, UNISINOS, UFBA e UFPEL). O trabalho em equipe formou rede de pesquisa para avaliar critérios de uso racional de água e eficiência energética em HIS em diferentes regiões nacionais. O relatório final, publicado por Ghisi et al. (2015d), apresenta informações sobre tecnologias para uso racional de água, geração de energia renovável e técnicas para melhorar os níveis de eficiência energética em HIS, evidenciando oportunidades para melhorar as práticas referentes às HIS nacionais.

É necessário estender as discussões sobre a adequação das HIS nacionais aos climas locais e às necessidades de seus usuários. Diferentes profissionais do mercado devem ser informados sobre aspectos impactantes na eficiência energética das HIS e as maneiras mais adequadas de incluí-los em seus projetos. Universidades e pesquisadores podem contribuir significativamente nesse cenário, principalmente ao apresentar as melhores soluções para diferentes climas nacionais e ao propor métodos de avaliação que podem ser replicados por profissionais de diferentes municípios.

De maneira geral, a literatura evidencia que os aspectos impactantes nos métodos vigentes do RTQ-R e da NBR 15575 são semelhantes (SILVA; GHISI, 2014c). Portanto, ao informar os profissionais e propor alternativas para que esses aspectos sejam considerados em suas práticas, um estoque de HIS energeticamente mais eficientes pode ser obtido. Sugere-se, portanto, a elaboração de manuais de projetos eficientes, como proposto por Miotto (2017) para a cidade de Foz do Iguaçu-PR; ou como a cartilha bioclimática para o município de Sinop-MT, proposta por Luz (2017). Ao considerar as perspectivas de profissionais locais durante a elaboração de manuais ou cartilhas, os resultados obtidos podem ser mais condizentes com a realidade e obter maior aceitação e uso. A elaboração de manuais dessa natureza pode minimizar problemas similares ao apresentado por Pacheco (2016): considerando-se que no Rio Grande do Norte existem duas ZBs principais (7 e 8), em algumas cidades, como as da região serrana, há particularidades que devem ser consideradas ao se projetar as habitações nessas localidades. Profissionais locais, por vivenciarem e também pelo melhor conhecimento dos climas das cidades em que trabalham, podem contribuir com perspectivas locais e aprimorar práticas genéricas.

Além da elaboração de manuais e cartilhas para aprimorar as práticas de projeto de HIS, a literatura também suporta a criação de cartilhas específicas para melhorar outros aspectos de uso das habitações. Alvares (2018) expõe que, muitas vezes, os moradores expandem as áreas construídas de suas residências, pois o projeto padrão é considerado pequeno. Portanto, é importante elaborar cartilhas que apresentem diretrizes para ampliações, considerando essa prática durante o projeto das HIS. Prever ampliações pode melhorar as dinâmicas de ventilação e iluminação da envoltória, uma vez que práticas de autoconstrução não seguem rigores técnicos. Outro aspecto que pode ser aprimorado no futuro é a maneira como os moradores interagem com suas habitações, dado que o mau uso dos sistemas pode comprometer o desempenho energético das HIS. Billerbeck (2015) sugere a elaboração de manuais sobre a utilização dessas tecnologias; afinal, aumentar o conhecimento dos usuários sobre o funcionamento dos sistemas é essencial para garantir 
desempenhos satisfatórios durante sua operação. Cartilhas expondo as tecnologias existentes que apresentem exemplos práticos e didáticos sobre como os sistemas impactam a conta de energia no fim do mês seriam uma opção viável para as comunidades. A literatura também evidencia a importância de conhecer os usos finais de energia elétrica em HIS nacionais: Silva et al. (2014) concluíram que a utilização de dados de monitoramento em campo é importante para estabelecer diretrizes para habitações e para elaborar políticas públicas. Conhecendo-se melhor as práticas dos moradores, as estratégias de redução de consumo, como as campanhas de conscientização e elaboração de cartilhas, podem ser mais efetivas.

\section{Síntese dos aspectos mais frequentes e sugestões para trabalhos futuros}

Apesar do volume de documentos revisados, uma limitação desse estudo está relacionada à grande variabilidade de métodos empregados na literatura: uso de cálculos e avaliações prescritivas, simulações computacionais com diferentes programas, avaliações em campo ou combinações desses métodos. Adicionado a isso, tem-se as escolhas dos parâmetros a serem estudados: alguns estudos focaram em avaliações sobre um aspecto enquanto outros avaliaram combinações de diferentes parâmetros; novamente, as especificidades são determinadas pelos responsáveis pelos estudos, e diferentes combinações foram testadas. Além disso, ainda existe a influência climática: cada estudo analisou uma cidade ou um grupo de cidades de ZBs variadas, dificultando a comparação dos resultados. Portanto, quantificar os aspectos mais impactantes à eficiência energética de HIS nacionais com base nesses estudos pode resultar em incertezas. Todavia, as frequências com que os aspectos foram estudados apontam o que os pesquisadores consideraram mais importante para incluir em seus estudos, e a Figura 9 apresenta o conjunto de aspectos mais frequentemente estudados na literatura nacional. Além de caracterizar a base nacional de dados, este conjunto representativo também pode ajudar estudos futuros quanto à escolha de parâmetros a serem avaliados.

Se por um lado a variabilidade de métodos empregados pode dificultar a determinação dos aspectos mais ou menos impactantes à eficiência energética, por outro lado, a aplicação desses métodos serve como base para estudos futuros. Entretanto, mais do que replicar as abordagens utilizadas, a síntese da literatura permite combiná-las a fim de obter resultados mais expressivos e comparáveis. Nesse sentido, ao se considerar as publicações de periódicos internacionais de extratos elevados (na maior parte das vezes resultantes de pesquisas de doutorado ou de colaboração entre grupos de pesquisadores), é possível avançar bastante na área. Os métodos aplicados anteriormente podem servir como base para que próximas pesquisas aprimorem as conclusões já obtidas.

Figura 9 - Aspectos mais frequentemente estudados na literatura

Selo Casa Azul

Sombreamento ${ }_{\text {Ventilação cruzada }}^{\text {Ocupa }}$

Aquecimento solar de água Comportamento dos usuários

Propriedades dos vidros Absortância da cobertura

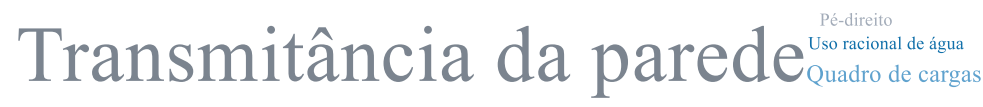

OrientaçãoTransmitância da cobertura

Área de abertura Absortância da parede

Condições de contorno Capacidade térmica da parede

Tipo da esquadria Capacidade térmica da cobertura

Emissividade da cobertura

280 Bavaresco, M. V.; Cuchivague, H. Y. O.; Schinazi, A.; Ghisi, E. 
Os estudos de Triana, Lamberts e Sassi (2015) e Ghisi et al. (2015c) foram importantes para determinar modelos de referência de HIS uni e multifamiliares. Triana, Lamberts e Sassi (2015) testaram o desempenho dos modelos representativos nas zonas bioclimáticas 3 e 8 . A partir dos resultados já apresentados pelos autores, e considerando-se os aspectos apresentados nessa revisão de literatura, um desafio à área é a realização de estudos com escopos ainda mais abrangentes. Nesse sentido, é possível utilizar simulações computacionais combinando-se os modelos representativos e variando-se os limites dos aspectos apresentados como impactantes à eficiência energética de HIS brasileiras nesta revisão. A consolidação do conhecimento produzido pode resultar em informações objetivas quanto às características de projeto, e também quanto à combinação de diversas características. Ao se aplicar os mesmos estudos de caso em diferentes regiões climáticas, seria possível quantificar o impacto de cada parâmetro quando submetido a condições específicas. A partir disso, estudos sobre o custo da aplicação dessas medidas pode favorecer a escolha, por parte de projetistas e construtoras, em relação às adequações que proporcionam os melhores custos-benefícios. Nesse sentido, o método aplicado por Tubelo et al. (2018) comprovou que composições mais complexas, mesmo otimizando o desempenho térmico, podem elevar o custo da obra em até $50 \%$. No entanto, os autores também apresentaram alternativas capazes de melhorar o desempenho térmico nas cidades avaliadas com acréscimos máximos de $10 \%$ no valor da obra. Adicionalmente às avaliações de custo, também realizadas por Dalbem et al. (2019), os autores evidenciaram a possibilidade de se utilizar normas internacionais para avaliar as HIS brasileiras. A aplicação do método pode embasar outros estudos quanto aos testes de classificações energéticas já consolidadas internacionalmente. Além de avaliar a viabilidade de classificações já consolidadas, esse tipo de resultado pode ajudar a aprimorar as classificações desenvolvidas no Brasil futuramente.

Considerando-se cenários futuros, a literatura também apresenta métodos sólidos para se avaliar o impacto das mudanças climáticas em HIS e a necessidade de se melhorar o desempenho das habitações (INVIDIATA; GHISI, 2016; INVIDIATA; LAVAGNA; GHISI, 2018; MONTES, 2016; TRIANA; LAMBERTS; SASSI, 2016, 2018). A utilização de medidas de eficiência energética em HIS, além de melhorar o desempenho térmico e energético das habitações atualmente, é capaz de favorecer o desempenho no futuro. Ao se melhorar as condições da envoltória, melhores condições de conforto são garantidas, reduzindo-se o risco do crescimento excessivo associado ao uso de aparelhos de ar-condicionado. Para integrar tudo isso em abordagens mais práticas, a literatura também apresenta proposições de projetos de habitações, como o apresentado por Mesquita e Kós (2017), que já incorpora estratégias bioclimáticas em sua concepção. De maneira geral, os estudos realizados sobre eficiência energética em HIS até agora podem servir como base para a realização de trabalhos futuros que combinem métodos já consolidados. A partir da determinação do status quo do setor de HIS, juntamente com avaliações amplas sobre quais parâmetros são os mais impactantes para cada zona bioclimáticas nacional, espera-se que as práticas de projeto das habitações sejam baseadas neste direcionamento.

Uma vez que combinar diversos métodos já consolidados seria uma tarefa bastante dispendiosa, é possível que novas redes de pesquisa sejam formadas. Nesse sentido, a literatura evidencia os avanços obtidos pela rede formada entre pesquisadores da UFSC, UFES, UFMS, UFPR, UNISINOS, UFBA e UFPEL (GHISI $e t$ al., 2015d). De maneira geral, ao se combinar centros de pesquisa, diferentes expertises são mescladas possibilitando avanços significativos na área. Além disso, cada grupo de pesquisa pode ficar responsável por conduzir partes específicas do projeto a fim de otimizar o desenvolvimento dos estudos. É possível apresentar mapas para os projetistas sobre os impactos de cada parâmetro no desempenho das HIS em diferentes climas nacionais, que, associados ao custo, podem guiar as escolhas futuras.

\section{Proposta de protocolo para que projetistas avaliem aspectos impactantes na eficiência energética de HIS}

Além de sintetizar os aspectos apresentados na literatura como impactantes à eficiência energética de HIS brasileiras, é importante criar alternativas para que esse assunto seja abordado por diferentes profissionais do setor da construção civil. É necessário que os projetistas conheçam termos relacionados à eficiência energética em edificações, bem como as propriedades termofísicas dos materiais e seus impactos no 
desempenho de edificações construídas em diferentes regiões. Criar soluções simplificadas pode ser uma alternativa inicial para incluir os projetistas nas avaliações dos projetos das HIS nacionais. Desta forma, estabeleceu-se um protocolo, apresentado na Figura 10, para sintetizar as informações obtidas com esta revisão de literatura. Ressalta-se que a intenção principal é apresentar um formulário simples para que os projetistas compreendam como as características de seus projetos se relacionam aos aspectos considerados importantes do ponto de vista energético.

Figura 10 - Protocolo de avaliação de aspectos impactantes no desempenho energético de HIS

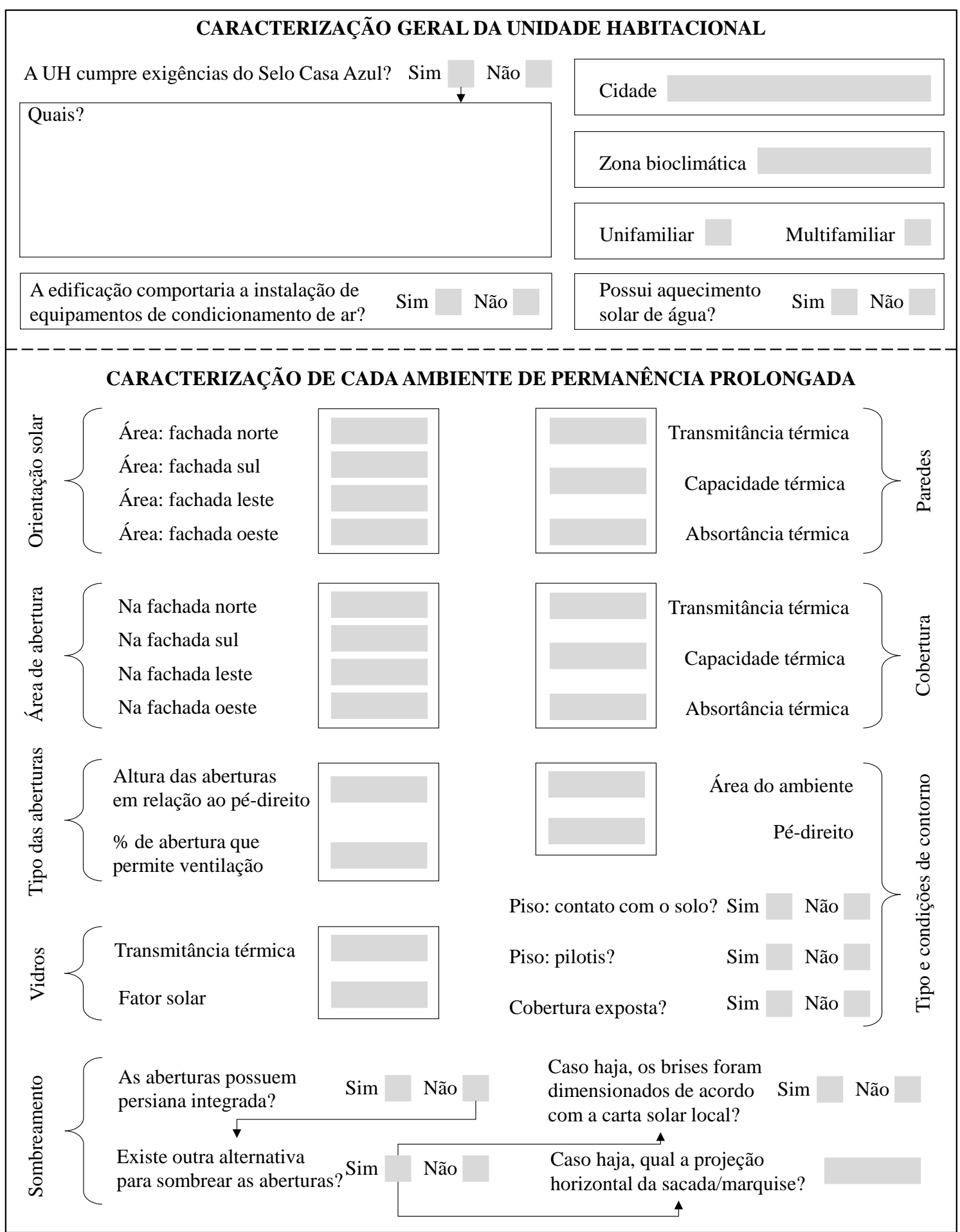

282 Bavaresco, M. V.; Cuchivague, H. Y. O.; Schinazi, A.; Ghisi, E. 
Apesar de a base principal para o desenvolvimento do protocolo ter sido esta revisão de literatura, ressalta-se que o mesmo também se adequa às exigências da Proposta de Instrução Normativa Inmetro para a Classe de Eficiência Energética de Edificações Residenciais - INI-R (CENTRO..., 2018). O protocolo apresenta os aspectos definidos como impactantes e determina que os responsáveis avaliem valores reais que os representem. Por exemplo: uma vez que orientação é um aspecto impactante à eficiência energética, o protocolo sugere que os projetistas calculem as áreas de fachada de cada orientação para os ambientes de permanência prolongada. De maneira similar, sugere-se que avaliem propriedades termofísicas (transmitância térmica, absortância e capacidade térmica) de paredes e coberturas. Por um lado, ao sintetizar todas as informações sobre as habitações projetadas, os profissionais entram em contato com valores práticos e podem associar as escolhas de projeto aos aspectos que influenciam a eficiência energética das habitações. Por outro lado, ao preencher o protocolo com as informações necessárias, pode-se avaliar de maneira simplificada o desempenho das habitações utilizando-se a interface web disponibilizada durante o desenvolvimento da INI-R. A interface ${ }^{1}$ exige algumas informações apresentadas no protocolo da Figura 10 para calcular o desempenho das habitações em termos de cargas térmicas para refrigeração e aquecimento, além dos percentuais de horas em conforto térmico quando a unidade habitacional é naturalmente ventilada.

Além de contribuir para a verificação das escolhas projetuais, o protocolo pode ter papel educativo a longo prazo. De maneira geral, ao se avaliar os projetos em relação ao seu desempenho energético, espera-se que conhecimentos técnicos sobre eficiência energética em edificações se tornem mais difundidos. A interface web, por sua vez, facilita a comparação rápida entre diferentes características construtivas, sem exigir simulações computacionais. Portanto, com a disseminação da ferramenta e com o uso frequente por parte dos projetistas, as melhorias nos processos de projeto podem ser contínuas: quanto maior for o entendimento dos impactos de diferentes aspectos na eficiência energética, maior pode ser a interface nas fases iniciais de projeto. Por fim, é provável que os modelos de certificação se tornem mais conhecidos, difundidos e utilizados, promovendo avanços no setor da construção civil nacional.

\section{Conclusões}

Neste artigo, revisou-se a literatura nacional referente à eficiência energética de habitações de interesse social (HIS). Ao longo do documento, apresentaram-se os principais aspectos que impactam o desempenho térmico e energético dessas habitações, bem como desafios, limitações e oportunidades para melhorar as práticas referentes às HIS nacionais, e espera-se que diferentes partes interessadas tenham acesso às informações. Por fim, foi proposto um protocolo para que os projetistas avaliem as características das habitações que estão relacionadas aos aspectos impactantes na eficiência energética das mesmas. De maneira geral, concluiu-se que:

(a) não se pode apresentar uma solução geral para melhorar o desempenho energético das HIS brasileiras, pois as escolhas devem ser condicionadas às realidades de cada local onde se pretende construir. Caso as habitações sejam construídas desconsiderando o clima local, baixos níveis de desempenho térmico serão obtidos; consequentemente, os moradores apresentarão insatisfação com suas residências;

(b) zonas bioclimáticas intermediárias têm menos volume de recomendações construtivas. Os estudos revisados focam, majoritariamente, em climas extremos e/ou medianos (e.g.: ZBs 1, 5 e 8), ou em climas de cidades mais populosas (e.g.: ZB 3, de São Paulo). No entanto, é importante que essas recomendações sejam apresentadas para o máximo de locais possível;

(c) além disso, algumas cidades apresentam condições climáticas específicas que merecem atenção: apesar de fazerem parte de uma mesma ZB, dois municípios podem apresentar particularidades que distinguem as recomendações construtivas para eles. Uma alternativa para esse problema é a inclusão de profissionais locais na determinação dessas recomendações e na elaboração de cartilhas e manuais para melhorar o desempenho das HIS. Ao se incluir os profissionais locais, a aceitação e o uso dos documentos elaborados podem aumentar;

(d) uma vez que conhecer o status quo do setor de HIS brasileiras é um passo importante para desenvolver políticas públicas, sugere-se que as construtoras e/ou instituições financeiras mantenham bases atualizadas de dados sobre as características das habitações construídas. Além de caracterizar o estoque construído, essa alternativa permitiria acompanhar as evoluções alcançadas nesse setor ao longo dos anos;

${ }^{1}$ Disponível em: http://pbeedifica.com.br/redes/residencial/. 
(e) juntamente com as características da envoltória, a dimensão humana também deve ser considerada como um dos aspectos impactantes no consumo energético das HIS. É necessário conhecer melhor as práticas, bem como capacitar moradores quanto ao funcionamento de tecnologias instaladas em suas habitações. Além dos projetistas, os fabricantes e vendedores de tecnologia podem contribuir com materiais educativos a fim de disseminar as melhores práticas para operação e controle dos sistemas instalados;

(f) o protocolo proposto para que projetistas avaliem a eficiência energética das HIS engloba os parâmetros necessários para avaliar o desempenho das habitações utilizando a interface web disponibilizada durante o desenvolvimento da INI-R. Ao facilitar a comparação entre habitações com diferentes características, os projetistas podem avaliar, de maneira prática e simplificada, como suas escolhas de projeto impactarão no desempenho da habitação construída. A longo prazo, o uso do protocolo e da interface web pode ter papel educativo e disseminar as ferramentas para avaliação de eficiência energética de edificações desenvolvidas no Brasil; e

(g) por fim, evidenciou-se a possibilidade de testar normas internacionais consolidadas a fim de adequá-las à realidade brasileira. Assim, além de avaliar a viabilidade dessas certificações energéticas, a experiência internacional pode conduzir os esforços nacionais nessa área visando melhorias contínuas.

\section{Referências}

AFFELDT, V. B. Desenvolvimento sustentável na habitação de interesse social: um estudo de caso sobre a percepção dos beneficiários do Programa Minha Casa Minha Vida, na cidade de Porto Alegre. Porto Alegre, 2015. 50 f. Trabalho de Conclusão de Curso (Graduação em Administração) - Universidade Federal do Rio Grande do Sul, Porto Alegre, 2015.

ALVARES, S. M. Desempenho térmico de habitações do PMCMV em paredes de concreto: estudo de caso em São Carlos-SP e diretrizes de projeto para a Zona Bioclimática 4. São Carlos, 2018. 143 f. Dissertação (Mestrado em Arquitetura e Urbanismo) - Universidade de São Paulo, São Carlos, 2018.

ALVARISTO, C. et al. Estudo da eficiência energética do sistema elétrico de Habitações de Interesse Social na cidade de Santa Rosa. In: SEMINÁRIO NACIONAL DE CONSTRUÇÕES SUSTENTÁVEIS, 4., Passo Fundo, 2015. Anais [...] Passo Fundo: IMED, 2015.

ALVES, A. F. M.; PEDRINI, A.; LIMA, G. L. F. Eficiência energética de edificações na zona bioclimática 08: diretrizes de projeto a partir do método prescritivo do RTQ-R. In: ENCONTRO NACIONAL DE TECNOLOGIA DO AMBIENTE CONSTRUÍDO, 14., Juiz de Fora, 2012. Anais [...] Juiz de Fora: ANTAC, 2012.

ANCHIETA, C. C. Regression models to assess the thermal performance of Brazilian low-cost houses: consideration of solar and shading devices. São Carlo, 2016. 160 f. Dissertação (Mestrado em Arquitetura e Urbanismo) - Universidade de São Paulo, São Carlos, 2016.

ANGELONI, P. D. et al. Verificação de alguns indicadores de sustentabilidade em HIS de Santa Rosa baseado no manual Selo Casa Azul Caixa. In: SIMPÓSIO INTERNACIONAL DE QUALIDADE AMBIENTAL, 11., Porto Alegre, 2018. Anais [...] Porto Alegre: PUCRS, 2018.

ARAGÃO, D. L. L. J.; HIROTA, E. H. Sistematização de requisitos do usuário com o uso da Casa da Qualidade do QFD na etapa de concepção de unidades habitacionais de interesse social no âmbito do Programa Minha Casa, Minha Vida. Ambiente Construído, Porto Alegre, v. 16, n. 4, p. 271-291, out./dez. 2016.

ASSOCIAÇÃO BRASILEIRA DE NORMAS TÉCNICAS. NBR 15220: desempenho térmico de edificações. Rio de Janeiro, 2005.

ASSOCIAÇÃO BRASILEIRA DE NORMAS TÉCNICAS. NBR 15575: edificações habitacionais: desempenho Rio de Janeiro, 2013.

AZEVEDO, L. D. P. Avaliação do ciclo de vida de diferentes envoltórias para habitações de interesse social na cidade de Florianópolis. Florianópolis, 2018. 120 f. Trabalho de Conclusão de Curso (Graduação em Engenharia Civil) - Universidade Federal de Santa Catarina, Florianópolis, 2018.

BALVEDI, B. F. et al. Identificação de perfis de comportamento do usuário para edificações residenciais multifamiliares e naturalmente ventiladas em Florianópolis. Ambiente Construído, Porto Alegre, v. 18, n. 3, p.149-160, jul./set. 2018. 
BARZAN NETO, A. Análise da eficiência energética de uma edificação residencial através da nova proposta brasileira de etiquetagem de edificações. Florianópolis, 2018. 64 f. Trabalho de Conclusão de Curso (Graduação em Engenharia Civil) - Universidade Federal de Santa Catarina, Florianópolis, 2018.

BATISTA, J. O. et al. Desempenho térmico de habitação multifamiliar do programa minha casa minha vida em Maceió - AL. In: ENCONTRO NACIONAL DE TECNOLOGIA DO AMBIENTE CONSTRUÍDO, 15., Maceió, 2014. Anais [...] Maceió: ANTAC, 2014.

BILLERBECK, C. Diferentes tipologias de edificações e o "ser sustentável" mediante o LEED e o CBCS. Guaratinguetá, 2015. 71 f. Trabalho de Conclusão de Curso (Graduação em Engenharia Civil) Universidade Estadual Paulista, Guaratinguetá, 2015.

BODACH, S.; HAMHABER, J. Energy efficiency in social housing: opportunities and barriers from a case study in Brazil. Energy Policy, v. 38, p. 7898-7910, 2010.

BRAGA, N. K. M. Potencial de aquecimento global de paredes de concreto a partir da avaliação do ciclo de vida. Brasília, 2018. 137 f. Dissertação (Mestrado em Engenharia Civil e Ambiental) Universidade de Brasília, Brasília, 2018.

BRAGA, W. R. O.; GABRIEL, C. P. C.; MOZENA, A. L. K. Metodologia para investigação dos impactos da incorporação do sistema de aquecimento solar de água em conjunto habitacional no município de Tupã. Periódico Eletrônico Fórum Ambiental da Alta Paulista, v. 12, n. 5, p. 60-72, 2016.

BRASILEIRO, A.; MORGADO, C.; LUZ, C. Conjunto do PMCMV no RJ: razões da (in)eficiência energética no decorrer de sua vida útil. In: ENCONTRO NACIONAL DE CONFORTO NO AMBIENTE CONSTRUÍDO, 14., Camboriu, 2017. Anais [...]Camboriu: ANTAC, 2017.

BRE, F. et al. building design optimisation using sensitivity analysis and genetic algorithm. Energy and Buildings, v. 133, p. 853-866, 2016.

BREITENBACH, L. G. Estudo e simulação de uma habitação de interesse social e sua relação com o regulamento técnico da qualidade para o nível de eficiência energética. São Leopoldo, 2015. 99 f. Dissertação (Mestrado em Engenharia Mecânica) - Universidade do Vale do Rio dos Sinos, São Leopoldo, 2015.

BRENNER, B. L. Avaliação da utilização de isolantes térmicos no interior das cavidades de blocos cerâmicos componentes de alvenarias de vedação externa para o clima de São Leopoldo, RS. São Leopoldo, 2017. 168 f. Dissertação (Mestrado em Engenharia Civil) - Universidade do Vale do Rio dos Sinos, São Leopoldo, 2017.

CAIXA ECONÔMICA FEDERAL. Minha Casa Minha Vida - Habitação Urbana: A grande chance de o trabalhador urbano morar no que é seu. 2020. Disponível em:

http://www.caixa.gov.br/voce/habitacao/minha-casa-minha-vida/urbana/Paginas/default.aspx. Acesso em: 10 fev. 2020.

CALDEIRA, D.; SPOSTO, R.; CALDAS, L. Avaliação do ciclo de vida energético da telha termoacústica com poliestireno expandido e telha cerâmica tipo plan em edificação unifamiliar. In: ENCONTRO NACIONAL DE TECNOLOGIA DO AMBIENTE CONSTRUÍDO, 16., São Paulo, 2016. Anais [...] São Paulo: ANTAC, 2016.

CARVALHO, D. S. Aspectos técnicos para a construção de edificação ecológica para baixa renda. Rio de Janeiro, 2018. 116 f. Trabalho de Conclusão de Curso (Graduação em Engenharia Civil) - Universidade Federal do Rio de Janeiro, Rio de Janeiro, 2018

CARVALHO, P. P. Desempenho térmico de habitações unifamiliares de interesse social com paredes de concreto armado na zona bioclimática 2 brasileira. Santa Maria, 2012. 109 f. Dissertação (Mestrado em Engenharia Civil e Ambiental) - Universidade Federal de Santa Maria, Santa Maria, 2012.

CASTRO FILHO, H. A. R. Percepção de empresas construtoras em relação aos programas de classificação de sustentabilidade de projetos de construção habitacional: um estudo de caso do Selo Casa Azul Caixa. Porto Alegre, 2013. 57 f. Trabalho de Conclusão de Curso (Graduação em Administração), Universidade Federal do Rio Grande do Sul, Porto Alegre, 2013. 
CECHINEL, R. J.; HACKENBERG, A. M.; TONDO, G. H. Desempenho térmico em habitações de interesse social inseridas na cidade de Joinville e recomendações para melhorias dos parâmetros mínimos construtivos. In: ENCONTRO NACIONAL DE TECNOLOGIA DO AMBIENTE CONSTRUÍDO, 16. Campinas, 2016. Anais [...] Campinas: ANTAC, 2016.

CENTRAIS ELÉTRICAS DE SANTA CATARINA S.A. Aquecedor solar composto de produtos descartáveis: manual de construção e instalação. 2009. Disponível em:

http://www.celesc.com.br/portal/images/arquivos/manuais/manual-aquecedor-solar.pdf. Acesso em: 15 jul. 2019.

CENTRO BRASILEIRO DE EFICIÊNCIA ENERGÉTICA EM EDIFICAÇÕES. Proposta de Instrução Normativa Inmetro para a Classe de Eficiência Energética de Edificações Residenciais. Florianópolis, 2018. Disponível em: http://cb3e.ufsc.br/sites/default/files/2018-09-25-INI-R\%20\%20Vers\%C3\%A3o02.pdf. Acesso em: 06 fev. 2020.

COELHO, I. S.; MARCON, J. B. Estratégias de baixo custo e sustentáveis para habitações de interesse social que proporcionem habitabilidade ao usuário tubaronense, utilizando como base o projeto da COHAB/SC. Tubarão, 2017. 107 f. Trabalho de Conclusão de Curso (Graduação em Engenharia Civil) Universidade do Sul de Santa Catarina, Tubarão, 2017.

CONTO, V. A sustentabilidade socioambiental de um empreendimento de habitação de interesse social através da aplicação do Selo Casa Azul Caixa. Santa Maria, 2017. 137 f. Dissertação (Mestrado em Engenharia de Produção) - Universidade Federal de Santa Maria, Santa Maria, 2017.

COSTA, S. R. G. D. Desempenho térmico e habitação: uma avaliação comparativa no contexto climático da zona bioclimática 8. Maceió, 2011. 145 f. Dissertação (Mestrado em Dinâmicas do Espaço Habitado) Universidade Federal de Alagoas, Maceió, 2011.

CRUZ, J. et al. Eficiência energética de diferentes sistemas construtivos avaliados segundo o método prescritivo do RTQ-R. In: CONFERÊNCIA INTERNACIONAL REGSA, Florianópolis, 2014. Anais [...] Florianópolis, 2014.

DALBEM, R. et al. Análise de sensibilidade para elevar o nível de eficiência energética de uma habitação de interesse social na zona bioclimática 1. In: ENCONTRO NACIONAL DE CONFORTO NO AMBIENTE CONSTRUÍDO, 14., Camboriu, 2017. Anais [...] Camboriu: ANTAC, 2017.

DALBEM, R. et al. Optimisation of a social housing for south of Brazil: from basic performance standard to passive house concept. Energy, v. 167, p. 1278-1296, 2019.

DANTAS, C. M. Avaliação térmica de habitações unifamiliares do Programa Minha Casa Minha Vida em Maceió-AL. Maceió, 2015. 149 f. Dissertação (Mestrado em Arquitetura e Urbanismo) - Universidade Federal de Alagoas, Maceió, 2015.

DAROS, C. Design para a sustentabilidade: oportunidades e inovação a partir dos hábitos de consumo na habitação de interesse social. Curitiba, 2013. 183 f. Dissertação (Mestrado em Design) - Universidade Federal do Paraná, Curitiba, 2013.

DÖRFLER, M. A.; KRÜGER, E. L. Avaliação dos impactos termo-energéticos da orientação solar em habitação de interesse social na Zona Bioclimática 01. In: ENCONTRO NACIONAL DE TECNOLOGIA DO AMBIENTE CONSTRUÍDO, 15., Maceió, 2014. Anais [...] Maceió: ANTAC, 2014.

DÖRFLER, M.; KRÜGER, E. Simulações de desempenho térmico de moradias do PMCMV em diferentes zonas bioclimáticas quanto aos aspectos de implantação, materialidade e sombreamento de aberturas. In: ENCONTRO NACIONAL DE TECNOLOGIA DO AMBIENTE CONSTRUIIDO, 16., São Paulo, 2016. Anais [...] São Paulo: ANTAC, 2016.

ELI, L. G. Avaliação de medidas de eficiência energética em uma edificação multifamiliar por meio do regulamento brasileiro de etiquetagem. Florianópolis, 2018. 100 f. Trabalho de Conclusão de Curso (Graduação em Engenharia Civil) - Universidade Federal de Santa Catarina, Florianópolis, 2018.

FERREIRA, C. C.; PEREIRA, I. M. Avaliação do desempenho térmico de habitação de interesse social de acordo com a NBR 15575, para as diversas zonas bioclimáticas. In: ENCONTRO NACIONAL DE TECNOLOGIA DO AMBIENTE CONSTRUÍDO, 14., Juiz de Fora, 2012. Anais [...] Juiz de Fora: ANTAC, 2012. 
FORTUNATO, R. A. A sustentabilidade na habitação de interesse social: estudos de caso em reassentamentos do programa Minha Casa, Minha Vida no Núcleo Urbano Central da Região Metropolitana de Curitiba - municípios de Curitiba e Fazenda Rio Grande. Curitiba, 2014. 379 f. Dissertação (Doutorado em Meio Ambiente e Desenvolvimento) - Universidade Federal do Paraná, Curitiba, 2014.

FREIRE, E. M. S. Eficiência energética em edificações residenciais sob a ótica do RTQ-R na cidade de Várzea Grande - MT: um estudo de caso. Cuiabá, 2014. 136 f. Dissertação (Mestrado em Engenharia de Edificações e Ambiental) - Universidade Federal de Mato Grosso, Cuiabá, 2014.

FROENER, M. S. Análise dos recursos necessários para obtenção do Selo Casa Azul em condomínios do Programa Minha Casa Minha Vida. Porto Alegre, 2013. 87 f. Trabalho de Conclusão de Curso (Graduação em Engenharia Civil) - Universidade Federal do Rio Grande do Sul, Porto Alegre, 2013.

GARCIA, T. S. Avaliação de conforto térmico dos apartamentos do BNH na cidade de Santos. São Paulo, 2015. 163 f. Dissertação (Mestrado em Engenharia Civil) - Universidade de São Paulo, São Paulo, 2015.

GHISI, E. et al. Uso racional de água e eficiência energética em habitações de interesse social: volume 1 - hábitos e indicadores de consumo de água e energia. Florianópolis, 2015. 91 f. Relatório de pesquisa Universidade Federal de Santa Catarina, Florianópolis, 2015a.

GHISI, E. et al. Uso racional de água e eficiência energética em habitações de interesse social: volume 2 - uso de fontes alternativas de água. Florianópolis, 2015. 38 f. Relatório de pesquisa - Universidade Federal de Santa Catarina, Florianópolis, 2015 b.

GHISI, E. et al. Uso racional de água e eficiência energética em habitações de interesse social: volume 3 - Eficiência energética. Florianópolis, 2015. 120 f. Relatório de pesquisa - Universidade Federal de Santa Catarina, Florianópolis, 2015c.

GHISI, E. et al. Uso racional de água e eficiência energética em habitações de interesse social Relatório técnico final: Convênio $n^{\circ}$ 01.10.0507.00. Rio de Janeiro, 2015. 175 f. Relatório de pesquisa FINEP: Financiadora de Inovação e Pesquisa, Rio de Janeiro, 2015d.

GIGLIO, T. G. F. Influência do usuário na economia de energia obtida por meio do uso de sistema de aquecimento solar de água em habitações de interesse social. Florianópolis, 2015. 259 f. Dissertação (Mestrado em Engenharia Civil) - Universidade Federal de Santa Catarina, Florianópolis, 2015.

GIGLIO, T.; SANTOS, V.; LAMBERTS, R. Analyzing the impact of small solar water heating sytems on peak demand and on emissions in the Brazilian context. Renewable Energy, v. 133, p. 1404-1413, 2019.

GIL, M. P. C. Simplificações na modelagem de habitações de interesse social no programa de simulação de desempenho térmico EnergyPlus. São Carlos, 2017. 145 f. Dissertação (Mestrado em Arquitetura e Urbanismo) - Universidade de São Paulo, São Carlos, 2017.

GONÇALVES JUNIOR, C. A. et al. O impacto do Programa Minha Casa, Minha Vida na economia brasileira: uma análise de insumo-produto. Ambiente Construído, Porto Alegre, v. 14, n. 1, p. 177-189, jan./mar. 2014

GUARDA, E. L. A. et al. Estratégias Construtivas Para Adequação da Envoltória de uma Habitação de Interesse Social às Zonas Bioclimáticas Mato-Grossenses. Engineering \& Science, v. 1, n. 7, p. 45-57, 2018.

INVIDIATA, A. et al. Análise do desempenho termo energético de habitações unifamiliares de interesse social através do método de simulação do regulamento brasileiro. In: ENCONTRO NACIONAL DE TECNOLOGIA DO AMBIENTE CONSTRUÍDO, 16., Porto Alegre, 2016. Anais [...] Porto Alegre: ANTAC, 2016.

INVIDIATA, A.; GHISI, E. Impact of climate change on heating and cooling energy demand in houses in Brazil. Energy and Buildings, v. 130, p. 20-32, 2016.

INVIDIATA, A.; GHISI, E. Life-cycle energy and cost analyses of window shading used to improve the thermal performance of houses. Journal of Cleaner Production, v. 133, p. 1371-1383, 2016.

INVIDIATA, A.; LAVAGNA, M.; GHISI, E. Selecting design strategies using multi-criteria decision making to improve the sustainability of buildings. Building and Environment, v. 139, p. 58-68, 2018. 
JAUDY, L. F. R. et al. Desempenho térmico e conservação de energia de habitação de interesse social em Cuiabá-MT. In: ENCONTRO NACIONAL DE CONFORTO NO AMBIENTE CONSTRUÍDO, 13., Campinas, 2015. Anais [...] Campinas: ANTAC, 2015.

KOWALTOWSKI, D. C. C. K. et al. As pesquisas sobre "Minha Casa Minha Vida" e o conforto ambiental. In: ENCONTRO NACIONAL DE CONFORTO NO AMBIENTE CONSTRUÍDO, 13., Campinas, 2015. Anais [...] Campinas: ANTAC, 2015.

LAMBERTS, R.; DUTRA, L.; PEREIRA, F. O. R. Eficiência Energética na Arquitetura. 3. ed. São Paulo: PW Editores, 2014.

LEDER, S. M.; OLIVEIRA, A. C. Percentual de abertura na fachada e tipos de fechamento no desempenho térmico da edificação. In: ENCONTRO NACIONAL DE CONFORTO NO AMBIENTE CONSTRUÍDO, 13., Campinas, 2015. Anais [...] Campinas: ANTAC, 2015.

LIMA, G.; PEDRINI, A.; ALVES, A. Avaliação do desempenho térmico de uma habitação de interesse social localizada no clima quente e úmido da cidade de Parnamirim/RN com base no método de simulação do RTQ-R. In: ENCONTRO NACIONAL DE TECNOLOGIA DO AMBIENTE CONSTRUÍDO, 14., Juiz de Fora, 2012. Anais [...] Juiz de Fora: ANTAC, 2012.

LIMA, J. B. A.; PRADO, R. T. A.; TABORIANSKI, V. M. Optimization of tank and flat-plate colletor of solar water heating system for single-family households to assure economic efficiency through the TRNSYS program. Renewable Energy, v. 31, p. 1581-1595, 2006.

LOGSDON, L. O Programa Minha Casa, Minha Vida em Cuiabá-MT: uma análise da qualidade dos projetos destinados às famílias de baixa renda. Florianópolis, 2012. 186 f. Dissertação (Mestrado em Arquitetura e Urbanismo) - Programa de Pós-Graduação em Arquitetura e Urbanismo, Universidade Federal de Santa Catarina, Florianópolis, 2012.

LOHMANN, A. Avaliação de assentamentos e habitações permanentes construídos após desastres naturais de 2008 no Vale do Itajaí, SC. Florianópolis, 2015. 256 f. Tese (Doutorado em Arquitetura e Urbanismo) - Universidade Federal de Santa Catarina, Florianópolis, 2015.

LUZ, E. G. Cartilha bioclimática para o município de Sinop-MT. Sinop, 2017. 10 f. Trabalho de Conclusão de Curso (Graduação em Engenharia Civil) - Universidade do Estado de Mato Grosso, Sinop, 2017.

MARAFON, C. Estratégias bioclimáticas em avaliação de desempenho térmico nas habitações de interesse social em Sinop - MT. Sinop, 2013. 10 f. Trabalho de Conclusão de Curso (Graduação em Engenharia Civil). Departamento de Engenharia Civil, Universidade do Estado de Mato Grosso, Sinop, 2013.

MESQUITA, L.; KÓS, J. R. Towards more resilient and energy efficient social housing in Brasil. Energy Procedia, v. 121, p. 65-70, 2017.

Ministério do DeSEnVOlViMEnTO REGIONAL. Programa Minha Casa Minha Vida Contratações Brasil (2009 - 2019). Disponível em: http://sishab.cidades.gov.br/novo_executivo/filtro. Acesso em: 11 fev. 2020.

MIOTTO, L. P. Eficiência energética aplicada a unidades habitacionais de interesse social: Manual de projeto para a cidade de Foz do Iguaçu/PR. Santa Maria, 2017. 31 f. Trabalho de Conclusão de Curso (Especialização em Eficiência Energética Aplicada aos Processos Produtivos), Universidade Federal de Santa Maria, Santa Maria, 2017.

MIYAZATO, T. Integração do Sistema de Aquecimento Solar (SAS) ao projeto de edificações residenciais. São Paulo, 2012. 215 f. Dissertação (Mestrado em Arquitetura e Urbanismo) - Universidade de São Paulo, São Paulo, 2012.

MONTEIRO, V. M. L. M. Por uma moradia termicamente confortável: proposta de habitação de interesse social com ênfase no conforto térmico. Natal, 2012. 141 f. Dissertação (Mestrado em Conforto no Ambiente Construído; Forma Urbana e Habitação) - Universidade Federal do Rio Grande do Norte, Natal, 2012.

MONTES, M. A. T. Abordagem integrada no ciclo de vida de habitação de interesse social considerando mudanças climáticas. Florianópolis, 2016. 473 f. Tese (Doutorado em Engenharia Civil) Departamento de Engenharia Civil, Universidade Federal de Santa Catarina, Florianópolis, 2016. 
MORAGA, G. L. Avaliação do Ciclo de Vida e simulação termoenergética em unidade habitacional unifamiliar do Programa Minha Casa Minha Vida. Porto Alegre, 2017. 161 f. Dissertação (Mestrado em Engenharia Civil). Universidade Federal do Rio Grande do Sul, Porto Alegre, 2017.

MORAIS, J. M. S. C. Ventilação natural em edifícios multifamiliares do "Programa Minha Casa Minha Vida". Campinas, 2013. 211 f. Tese (Doutorado em Arquitetura, Tecnologia e Cidade) - Faculdade de Engenharia Civil, Arquitetura e Urbanismo, Universidade Estadual de Campinas, Campinas, 2013.

MORAIS, J. M. S. C.; LABAKI, L. C. CFD como ferramenta para simular ventilação natural interna por ação dos ventos: estudos de caso em tipologias verticais do "Programa Minha Casa, Minha Vida".

Ambiente Construído, Porto Alegre, v. 17, n. 1, p. 223-244, jan./mar. 2017.

MORENO, A. C. R.; MORAIS, I. S.; SOUZA, R. V. G. Thermal performance of social housing: a study based on Brazilian regulations. Energy Procedia, v. 111, p. 111-120, 2017.

MORGAN, A. Análise do consumo energético de habitações de interesse social (HIS) visando a economia de energia nas edificações. Santa Maria, 2014. 36 f. Trabalho de Conclusão de Curso (PósGraduação em Eficiência Energética Aplicada aos Processos Produtivos) - Universidade Federal de Santa Maria, Santa Maria, 2014.

MOTA, R. R. S. et al. Eficiência energética em residências: adequação dos parâmetros de uso e ocupação preconizados no RTQ-R à realidade de uma HIS em Pelotas - ZB2. Revistas Destaques Acadêmicos, v. 7, n. 4, p. 211-229, 2015.

MOTA, R. R. S.; CUNHA, E. G. Análise das condições de uso e ocupação de HIS, localizadas na cidade de Pelotas - ZB2, preconizadas no RTQ-R no método de simulação computacional. Cadernos De PósGraduação Em Arquitetura E Urbanismo, v. 16, n. 2, 2016.

OLIVEIRA, L. S. et al. Importância da definição da temperatura do solo para o processo de simulação termoenergética de edificações. In: ENCONTRO NACIONAL DE TECNOLOGIA DO AMBIENTE CONSTRUÍDO, 14., Juiz de Fora, 2012. Anais [...] Juiz de Fora: ANTAC, 2012.

OLIVEIRA, L.; SILVA, A. C. S. B.; PINTO, M. M. Avaliação dos limites das propriedades térmicas dos fechamentos opacos da NBR 15220-3, para habitações de interesse social, da Zona Bioclimática 2. In: ENCONTRO NACIONAL DE TECNOLOGIA DO AMBIENTE CONSTRUÍDO, 15., Maceió, 2014. Anais [...] Maceió: ANTAC, 2014.

PACHECO, G. H. S. Determinação de recomendações bioclimáticas para habitação de interesse social de quatro climas do Rio Grande do Norte. Natal, 2016. 131f. Dissertação (Mestrado em Arquitetura e Urbanismo) - Centro de Tecnologia, Universidade Federal do Rio Grande do Norte, Natal, 2016.

PALACIO, C. D. U. Energia incorporada de vedações para habitação de interesse social considerandose o desempenho térmico: estudo de caso com utilização do light steel frame no entorno do DF. Brasília, 2013. 123 f. Dissertação (Mestrado em Engenharia Civil e Ambiental) - Universidade de Brasília, Brasília, 2013.

PAULA, P. R. F. Avaliação do desempenho higrotérmico de casas de gesso no Brasil. Porto, 2017. 1855 f. Tese (Doutorado em Engenharia Civil) - Universidade do Porto, Porto, 2017.

PEREIRA, C. D.; GHISI, E. The influence of the envelope on the thermal performance of ventilated and occupied houses. Energy and Buildings, v. 43, p. 3391-3399, 2011.

PEREIRA, C. D.; GHISI, E.; GÜTHS, S. Comparação do desempenho térmico de revestimentos brancos. Paranoá: Cadernos De Arquitetura e Urbanismo, v. 12, p. 65-72, 2014.

POSSANI, R. D. Estudo da implantação de unidades habitacionais do programa minha casa minha vida em relação a parâmetros de conforto ambiental. Campo Mourão, 2015. 72 f. Trabalho de Conclusão de Curso (Bacharelado em Engenharia Civil) - Universidade Tecnológica Federal do Paraná, Campo Mourão, 2015.

PROVENZANO, D. C.; BASTOS, L. E. G. Avaliação da sustentabilidade de um empreendimento de HIS do PMCMV, através do Selo Casa Azul. Mix Sustentável, v. 3, n. 2, p. 14-23, 2017.

QUIRINO, L.; VAZ, Y.; LEDER, S. Iluminação natural na habitação de interesse social: proposta de abertura em diferentes localidades do Brasil. In: ENCONTRO NACIONAL DE CONFORTO NO AMBIENTE CONSTRUÍDO, 14., Camboriu, 2017. Anais [...] Camboriu: ANTAC, 2017. 
RIBEIRO, J. R. Estudo de viabilidade de implementação de unidades habitacionais sustentáveis de interesse social na cidade de Campo Mourão-PR. Campo Mourão, 2014. 57 f. Trabalho de Conclusão de Curso (Graduação em Engenharia Civil) - Universidade Tecnológica Federal do Paraná, Campo Mourão, 2014.

RIBEIRO, M. F. Inclusão social dos usuários de baixa renda por meio do sistema de aquecimento solar. Campinas, 2010. 217 f. Dissertação (Mestrado em Engenharia Civil) - Universidade Estadual de Campinas, Campinas, 2010.

RIOS, G. A. A. Desempenho termoenergético de edificação de interesse social. Ilha Solteira, 2015. 147 f. Tese (Doutorado em Engenharia Elétrica) - Universidade Estadual Paulista Julio de Mesquita Filho, Ilha Solteira, 2015.

RIOS, G. A. A. et al. Coberturas de cor branca como estratégia de redução de energia e de emissões de carbono. Revista de Engenharia e Tecnologia, v. 9, p. 76-90, 2017.

RODRIGUES, T. T.; OLIVEIRA, C.; CARLO, J. Níveis de eficiência da envoltória de unidades habitacionais do Programa Minha Casa Minha Vida em Zonas Bioclimáticas de 5 a 8. In: ENCONTRO NACIONAL DE CONFORTO NO AMBIENTE CONSTRUÍDO, 13., Campinas, 2015. Anais [...] Campinas: ANTAC, 2015

RORIZ BIOCLIMÁTICA. ZBBR: Zoneamento Bioclimático do Brasil. 29 abr. 2005 Disponível em: http://www.roriz.eng.br/download_6.html. Acesso em: 11 fev. 2020.

RUBIN, G. R.; BOLFE, S. A. O desenvolvimento da habitação de interesse social no Brasil. Ciência e Natura, v. 36, n. 2, p. 201-213, 2014.

SANTO, A. D. O impacto da janela no conforto térmico: edificações multifamiliares ventiladas naturalmente. Vitória, 2014. 121 f. Dissertação (Mestrado em Engenharia Civil) - Universidade Federal do Espírito Santo, Vitória, 2014.

SANTOS, A.; VOLPATO, T. C.; KOOP, M. Agenda de inovação para luminárias voltadas à habitação de interesse social. Projetica - Revista Científica de Design, v. 6, n. 2, p. 134-143, 2015.

SERBENA, H. J. Plataforma de luminária LED para habitação de interesse social. Curitiba, 2013. 185f. Dissertação (Metrado em Design, do Setor de Artes, Comunicação e Design) - Universidade Federal do Paraná, Curitiba, 2013.

SILVA, A. S. et al. Knowing electricity end-uses to successfully promote energy efficiency in buildings: a case study in low-income houses in Southern Brazil. Journal of Sustainable Energy Planning and Management, v. 2, p. 7-18, 2014.

SILVA, A. S.; ALMEIDA, L. S. S.; GHISI, E. Análise de incertezas físicas em simulação computacional de edificações residenciais. Ambiente Construído, Porto Alegre, v. 17, n. 1, p. 289-303, jan./mar. 2017.

SILVA, A. S.; ALMEIDA, L. S. S.; GHISI, E. Decision-making process for improving thermal and energy performance of residential buildings: A case study of constructive systems in Brazil. Energy and Buildings, v. 128 , p. $270-286,2016$

SILVA, A. S.; GHISI, E. Análise comparativa dos resultados do desempenho térmico da envoltória de uma edificação residencial pelos métodos de simulação do RTQ-R e da NBR 15575-1. Ambiente Construído, Porto Alegre, v. 14, n. 1, p. 215-230, jan./mar. 2014c.

SILVA, A. S.; GHISI, E. Análise de sensibilidade global dos parâmetros termofísicos de uma edificação residencial de acordo com o método de simulação do RTQ-R. Ambiente Construído, Porto Alegre, v. 13, n. 4, p. 135-148, out./dez. 2013.

SILVA, A. S.; GHISI, E. Uncertainty analysis of the computer model in building performance simulation. Energy and Buildings, v. 76, p. 258-269, 2014a.

SILVA, A. S.; GHISI, E. Uncertainty analysis of user behaviour and physical parameters in residential building performance simulation. Energy and Buildings, v. 76, p. 381-391, 2014b.

SILVA, D. C. Avaliação da sustentabilidade em edifícios multifamiliares do Programa Minha Casa Minha Vida em Criciúma, SC, segundo o Selo Casa Azul. Florianópolis, 2016. 270 f. Dissertação (Mestrado em Arquitetura e Urbanismo) - Universidade Federal de Santa Catarina, Florianópolis, 2016. 
SILVA, J. M. et al. Eficiência energética através do aproveitamento da iluminação natural em habitações de interesse social - estudo de caso. Gedecon - Gestão e Desenvolvimento em Contexto, v. 5, n. 1, p. 110114, 2017.

SILVA, M. S. R. Análise das práticas de sustentabilidade do assentamento Margem Esquerda em Gaspar/SC: utilizando os critérios do Selo Casa Azul. Florianópolis, 2012. 154 f. Dissertação (Mestrado em Arquitetura e Urbanismo) - Universidade Federal de Santa Catarina, Florianópolis, 2012.

TRIANA, M. A.; LAMBERTS, R. Proposta de incorporação de estratégias para melhoria de desempenho térmico e uso racional de energia em projeto de habitação de interesse social em Florianópolis. In: ENCONTRO NACIONAL DE CONFORTO NO AMBIENTE CONSTRUÍDO, 12., Brasília, 2013. Anais [...] Brasília: ANTAC, 2013.

TRIANA, M. A.; LAMBERTS, R.; SASSI, P. Characterisation of representative building typologies for social housing projects in Brazil and its energy performance. Energy Policy, v. 87, p. 524-541, 2015.

TRIANA, M. A.; LAMBERTS, R.; SASSI, P. Desempenho de habitações de interesse social frente às mudanças climáticas. In: ENCONTRO NACIONAL DE TECNOLOGIA DO AMBIENTE CONSTRUÍDO, 16., São Paulo, 2016. Anais [...] São Paulo: ANTAC, 2016.

TRIANA, M. A.; LAMBERTS, R.; SASSI, P. Should we consider climate change for Brazilian social housing? Assessment of energy efficiency adaptation measures. Energy and Buildings, v. 158, p. 1379$1392,2018$.

TSURUDA, L. K. et al. Evaluations of Energy Efficiency and Economic Impact of the application of Retrofit Lighting in Popular Housing. In: CHILEAN CONFERENCE ON ELECTRICAL, ELECTRONICS ENGINEERING, INFORMATION AND COMMUNICATION TECHNOLOGIES, Pucon, 2017. Proceedings [...] Pucon: IEEE, 2017.

TUBELO, R. et al. Cost-effective envelope optimisation for social housing in Brazil's moderate climate zones. Building and Environment, v. 133, p. 213-227, 2018.

VALDENEBRO, E.; DIETRICH, U.; INO A. Thermal comfort analysis of a representative multi-story social housing unit with woods as alternative construction material in Brazil. In: EMERGING CONCEPTS FOR SUSTAINABLE BUILT ENVIRONMENT, Helsinki, 2019. Proceedings [...] Helsinki: IOP Publishing, 2019.

VEIGA, R. K. S. Análise dos parâmetros de entrada para a predição da carga térmica de uma residência multifamiliar através da nova proposta do regulamento brasileiro de etiquetagem. Florianópolis, 2018. 102 f. Trabalho de Conclusão de Curso (Graduação em Engenharia Civil) Universidade Federal de Santa Catarina, Florianópolis, 2018.

VIEIRA, A. S. Uso racional de água em habitações de interesse social como estratégia para a conservação de energia em Florianópolis, Santa Catarina. Florianópolis, 2012. 172 f. Dissertação (Mestrado em Engenharia Civil) - Universidade Federal de Santa Catarina, Florianópolis, 2012.

VIEIRA, A. S.; GHISI, E. Water-energy nexus in low-income houses in Brazil: the influence of integrated on-site water and sewage management strategies on the energy consumption of water and sewerage services. Journal of Cleaner Production, v. 133, p. 145-162, 2016.

VIER, L. C. et al. Aquecimento Solar em Habitações de Interesse Social: Um Estudo de Caso em Santa Rosa - RS. In: SEMINÁRIO NACIONAL DE CONSTRUÇÕES SUSTENTÁVEIS, 4., Passo Fundo, 2015. Anais [...] Passo Fundo: ANTAC, 2015.

XIMENES, D. S. S.; TEIXEIRA, C. C. A Inserção da Qualidade Ambiental Urbana no Conjunto Habitacional de Interesse Social Zorilda. In: SUSTAINABLE URBAN COMMUNITIES TOWARDS A NEARLY ZERO IMPACT BUILT ENVIRONMENT, Vitória, 2016. Proceedings [...] Vitória, 2016. 


\title{
Mateus V. Bavaresco
}

Departamento de Engenharia Civil | Universidade Federal de Santa Catarina | Rua João Pio Duarte da Silva, 205, Córrego Grande | Florianópolis - SC - Brasil | CEP 88040-900 | Tel.: (48) 3721-5184 | E-mail: bavarescomateus@gmail.com

\section{Hamilton Yair Ortiz Cuchivague}

Mitsidi Projetos | Rua Bela Cintra, 478, Consolação | São Paulo - SP - Brasil | CEP 01415-000 | Tel.: (11) 3159-3188 | E-mail: hamilton@mitsidi.com

\section{Alexandre Schinazi}

Mitsidi Projetos | E-mail: alexandre@mitsidi.com

\section{Enedir Ghisi}

Departamento de Engenharia Civil | Universidade Federal de Santa Catarina | Tel.: (48) 3721-2115 | E-mail: enedir.ghisi@ufsc.br

\author{
Ambiente Construído \\ Revista da Associação Nacional de Tecnologia do Ambiente Construído \\ Av. Osvaldo Aranha, $99-3^{\circ}$ andar, Centro \\ Porto Alegre - RS - Brasil \\ CEP 90035-190 \\ Telefone: +55 (51) 3308-4084 \\ Fax: +55 (51) 3308-4054 \\ www.seer.ufrgs.br/ambienteconstruido \\ E-mail: ambienteconstruido@ufrgs.br
}

(c) (i) This is an open-access article distributed under the terms of the Creative Commons Attribution License.

292 Bavaresco, M. V.; Cuchivague, H. Y. O.; Schinazi, A.; Ghisi, E. 